\title{
Beads on a Chain (BoC) Fluorescent Oligomeric Materials: Interactions of Conjugated Organic Cross-linkers with Silsesquioxane Cages
}

Shahrea Mahbub, ${ }^{a}$ Sukanya Saha, ${ }^{b}$ Guda Ramakrishna ${ }^{b}$ Joseph C. Furgal ${ }^{a}$

${ }^{a}$ Department of Chemistry and Center for Photochemical Sciences Bowling Green State

University, Bowling Green, $\mathrm{OH},{ }^{b}$ Department of Chemistry and Biochemistry Western Michigan University, Kalamazoo, MI

\begin{abstract}
Organic electronic materials have advantages over inorganics in terms of versatility, cost and processability. Recent advancements in organic materials for light emitting diodes (OLED), field effect transistors (OFET), and photovoltaics have engendered extensive innovation potential on this field. In this research, we focus on synthesizing SQ (silsesquioxane) based oligomers crosslinked by di-bromo-aromatic linkers and explore how the cross-linker and oligomer length influence their photophysical properties. Bis-tri-alkoxy silyl (linker) model compounds were synthesized to compare non-cage photophysical properties with the oligomers. Several techniques such as UV/Vis, fluorescence, FTIR, thermal gravimetric analysis (TGA) have been used to characterize the systems. Time-resolved fluorescence and femtosecond transient absorption spectroscopy are used to understand the excited state dynamics of these materials. Studies are carried out to understand the differences between monomers and oligomers and potential energy transfer and charge transfer between the cages and cross-linking chromophores. Transient absorption showed lower energy absorption from the excited states, suggesting short range communication between moieties. Single photon counting studies have shown distinct lifetime differences between most linkers and cages showing possible excitation energy transfer through these materials. Transient absorption anisotropy measurements have shown signatures for excitation energy transfer between linker chromophores for oligomeric compounds. The silsesquioxane (SQ) backbone of the oligomers gives substantial thermal stability as well as solution processability, giving better flexibility for achieving energy transfer between linking chromophores.
\end{abstract}

\section{Introduction}

Organic oligomeric materials have drawn considerable interest in the field of electronics over the last several years. Organic light-emitting diodes (OLEDs) for flat panel displays and lighting; field-effect transistors for display backplanes and disposable electronics; photodetectors; and organic photovoltaics (OPVs) ${ }^{1-4}$ are some of the widespread uses of them., ${ }^{5,6,15-19,7-14}$ Organic electronic materials have many advantages over inorganics due to low costs, easy processability from low densities with high solubilities, and material tunability. ${ }^{20-23}$ One challenge to implementation is an advanced understanding of the necessary materials structure-function characteristics for transporting charges in the conjugated matrix. Solubility is also a major drawback in terms of processability of conjugated oligomeric systems use in many electronic and photonic applications.

In our research, we are most interested in investigating the photonic properties of SQ based materials (polymers, oligomers, dendrimers, etc.), which have potential for application in the 
above-mentioned applications. Our efforts in this area have focused on synthesizing beads on a chain $(\mathrm{BoC})$ structures, which are SQs coupled with conjugated cross-linkers. Our designed $\mathrm{BoC}$ system consists of phenyl cross-linkers connected by vinyl groups on the corners of SQ cages. These materials provide a wide range of solubilities in different solvents which can give better processability. Also, they have high thermal stability (up to $500{ }^{\circ} \mathrm{C}$ ).

There have been many developments in hybrid materials derived from silsesquioxanes (SQ) in recent years. ${ }^{24-32}$ The term silsesquioxane refers to all structures with the empirical formula $\mathrm{RSiO}_{1.5}$, where $\mathrm{R}$ is hydrogen or any alkyl, alkylene, aryl, arylene, or organofunctional derivative of alkyl, alkylene, aryl, or arylene groups. ${ }^{33,34}$ Many application areas have emerged for SQ-based materials, including biomaterials, dielectric materials, and those for organic light emitting diode devices. ${ }^{11,35-38}$ SQ's have positive implications due to their better solubility and luminescence efficiency over many non-hybrid conjugated oligomers. ${ }^{11}$ A wide variety of research has been conducted on SQ based systems towards developing materials applicable in electronic and photonic applications. ${ }^{39}$ Most of these studies have been dedicated to the chromophore functionalization of SQ cages at each cage corner ${ }^{40-44}$ monofunctionalization of one corner, ${ }^{45-47}$ or their use as conjugated oligomer stabilizers. ${ }^{11,35}$ Sellinger et al. used mono and multifunctionalized $\mathrm{T}_{8}$ cage systems with fluorene based conjugated moieties for applications as OLED emitters. ${ }^{11}$ Froelich et al. has reported fluorene based SQ systems as emitters with tunable color ranges. ${ }^{36}$ With many of these studies it has been found that there are significant interactions either between the chromophore moieties or between the cage and chromophore. ${ }^{43,48,49}$

However few researchers have looked at gaining a better understanding of the photophysical and/or electronic properties of silsesquioxanes with bridging conjugated organic groups, with the majority focus being toward application driven light emitting or photoresponsive network materials. ${ }^{45,50-53}$ Less study has been devoted to linked soluble (lightly branched) SQs (Beads on a Chain, BoC), which we expand on in this work. ${ }^{54-60}$ Asuncion and Laine developed the earliest examples of $\mathrm{BoC}$ systems having unique photophysical properties. They used fluoride catalysis to rearrange cages into mixed functionalities with bromostyrenyl/phenyl units as one component and vinyl/phenyl units as a second component to form mixed $T_{10} / T_{12}$ cages which were coupled using Heck cross-coupling reactions to form 1,4-divinylbenzene conjugated organic bridges. ${ }^{54}$ Surprisingly, photophysical property analysis using steady state methods found significant redshifts in their fluorescence spectra versus model structures, but little to no shift in the absorption spectra, suggesting excimer or excited state conjugation interactions. This study led to a simplification of the reaction methods with longer oligomers by synthesizing SQs with phenyl and/or stilbene substitutions with vinyl groups for linkage with 4,4'-dibromostilbene and 1,4dibromobenzene.${ }^{56}$ Recent work by Dudziec et al. has also incorporated conjugated organic groups as linkers between double-decker phenyl SQs with hydrosilylation reactions, which adds an aliphatic bridge between the SQ and the conjugated portion of the linker. ${ }^{58}$ In their study absorption spectra were similar to the conjugated linkers, however no emissive properties were studied, so it is unknown if the emission red-shifts found for directly conjugated systems are present. Laine et al. have built on these double-decker phenyl SQ studies, and directly conjugated to the cage system through Heck cross coupling, a large set of conjugated cross-linkers, including carbazoles and thiophenes. ${ }^{57}$ Similar to the initial BoC systems with divinylbenzene links, they found red-shifted emission spectra and further conjugation enhancements versus model compounds. ${ }^{54}$ They further extended this work to include conjugated cross-links between phenyl-based ladder SQ's. ${ }^{61}$ These also show extended 3D conjugation effects in the excited state even though there is no cage structure. We have also built on SQ BoC research by studying the use of amine based ligands 
between $\mathrm{PhT}_{10} / \mathrm{T}_{12}$ mixed cage systems for use as solid-state and solution phase zinc ion fluorescence sensors. ${ }^{60}$

In addition to the novel photophysical properties found in these previous systems, interesting charge/energy transfer interactions are expected between the cage and conjugated moieties. In a study by Laine and co-workers, they have shown strong coupling between aromatics around the cage and conjugated linker molecules. ${ }^{54}$ In this study, we seek to gain a better understanding of interactions in an electronically diverse set of conjugated linkers with SQs using steady state and ultrafast spectroscopic techniques (Scheme 1), and how the oligomeric materials compare to their respective non-cage model compounds (Scheme 2), with the intention of further gauging the photophysical property effects of SQ cages and their polymers.
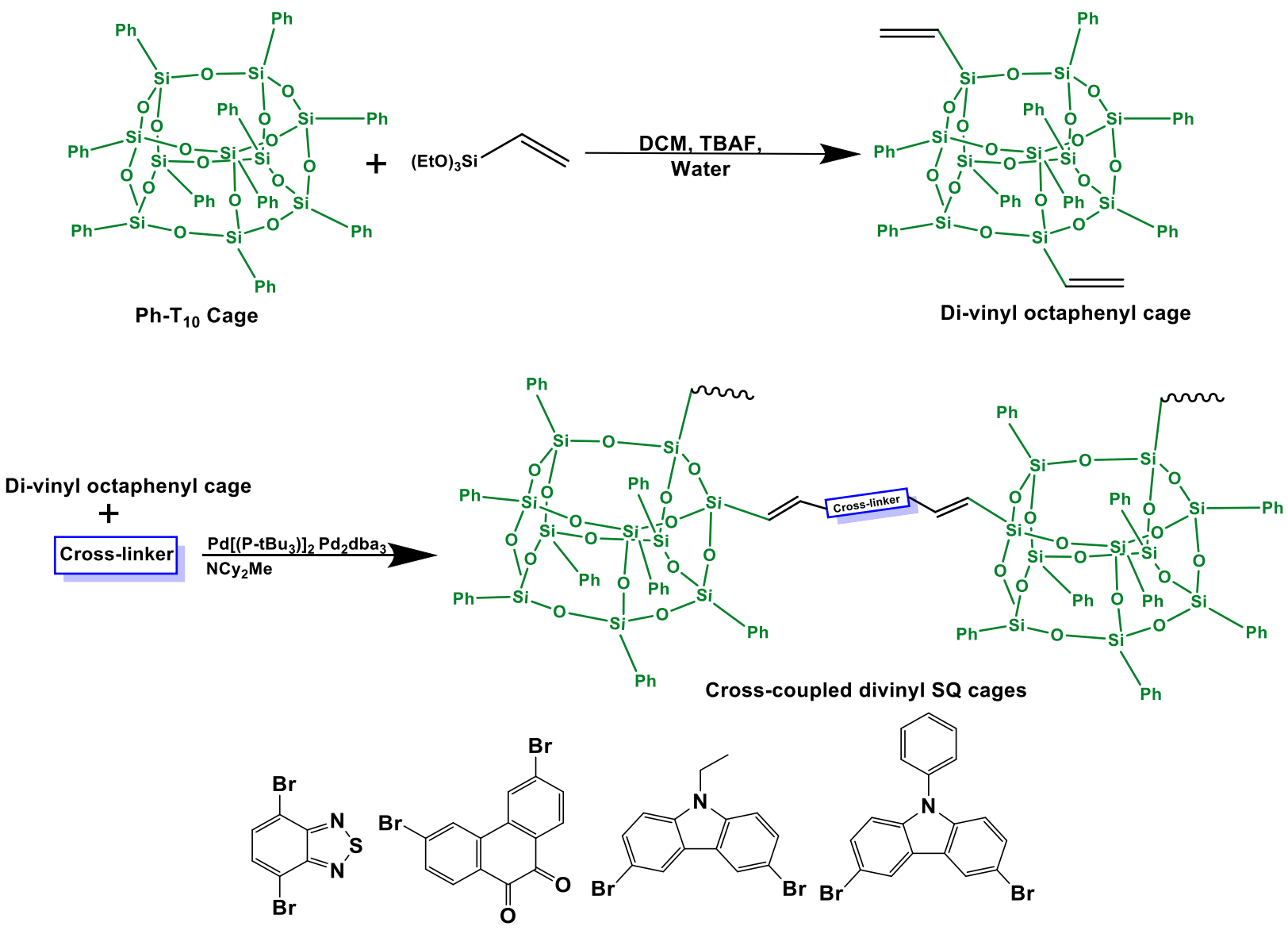

Scheme 1: Incorporation of vinyl groups into a $\mathrm{Ph}-\mathrm{T}_{10}$ cage with ratio controlled statistically to give $\sim 2$ groups per cage and cross-coupling of the divinyl substituted cage with organic linkers.

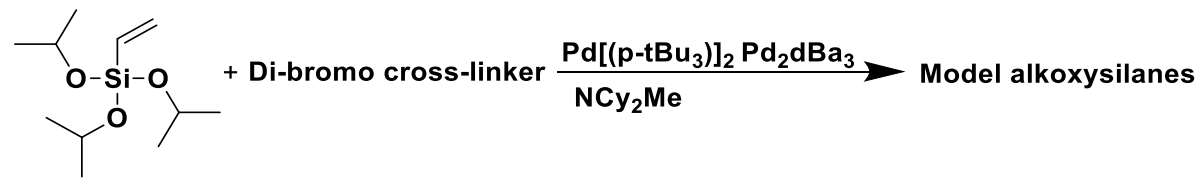




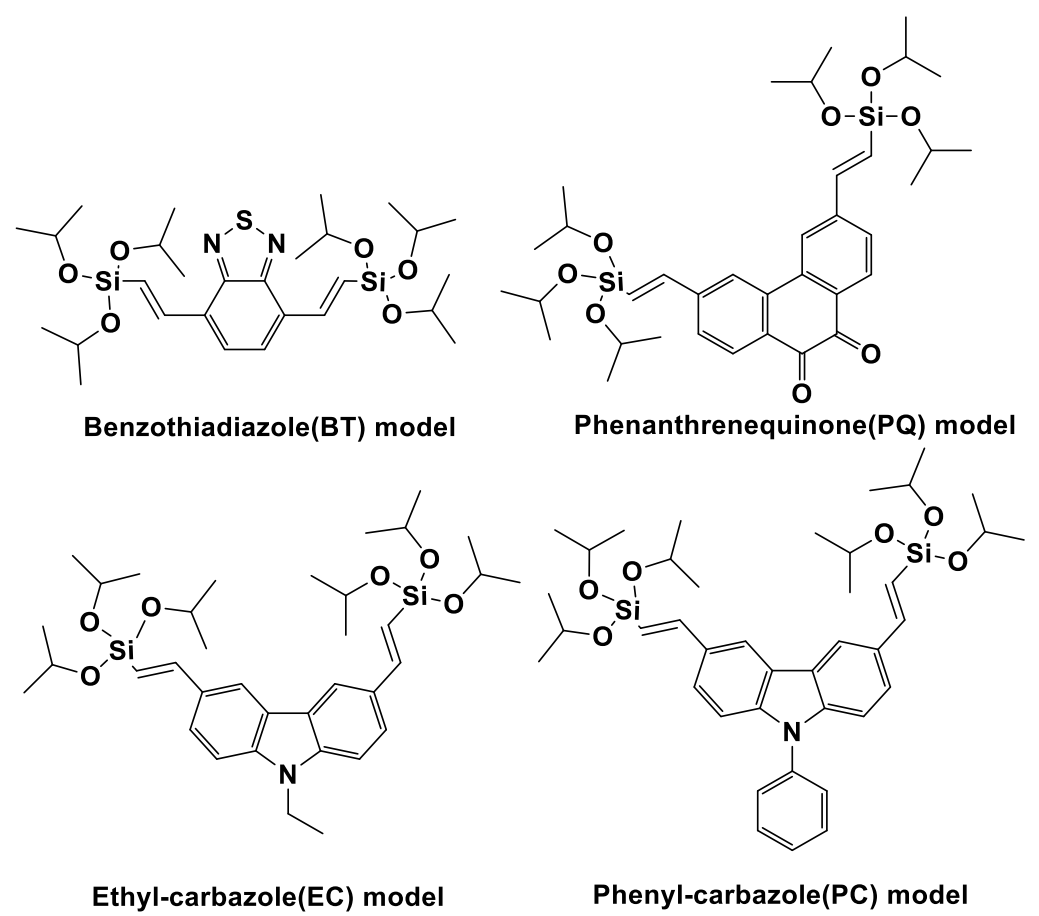

Scheme 2: Synthesis method of model compounds with cross-linkers: Benzothiadiazole (BT), Phenanthrenequinone (PQ), Ethyl-carbazole (EC) and Phenyl-carbazole (PC) respectively.

Experimental section

Materials

All the chemicals and solvents were purchased from commercially available sources. Tetrahydrofuran (THF), anhydrous 1,4-dioxane and N,N-dicyclohexylmethylamine were purchased from Fisher Scientific. THF was distilled before use under $\mathrm{N}_{2}$ from benzophenone and Na. OPS (Octaphenylsilsesquioxane) was a gift from Mayaterials Inc. Cross-linkers 4,7-dibromo2,1,3-benzothiadiazole were purchased from TCI America; 3,6-dibromophenanthrene-9,10-dione, 3,6-dibromo-9-ethylcarbazole and 3,6-dibromo-9-phenylcarbazole were purchased from SigmaAldrich. Bis(tri-tert-butylphosphine) palladium(0) and tris(benzylideneacetone) dipalladium(0) catalysts were purchased from TCI America and Acros Organics respectively and used as received.

\section{Analytical methods}

Gel Permeation Chromatography (GPC)

GPC analyses were done using Styragel columns (7.8 x $300 \mathrm{~mm}$ HR 0.5, 1, 3 and 4) with a RID10A RI detector (Shimadzu) with THF as the eluent at $30{ }^{\circ} \mathrm{C}$ and a flow rate of $1 \mathrm{~mL} / \mathrm{min}$. Polystyrene was used as the calibration standard and toluene as the reference. LC solution was used as the operating and analysis software.

\section{Fourier Transform Infrared Spectroscopy (FTIR)}

FTIR spectra were recorded using a Nicolet iS-50 FTIR spectrometer (Thermo Fisher Scientific) with an ATR crystal. Pure samples were placed on a ZnSe crystal for sample analysis and were scanned in the range from $4000-400 \mathrm{~cm}^{-1}$ with 32 scans.

\section{Thermal Gravimetric Analysis (TGA)}


Thermal stabilities and ceramic yields (\%) were calculated using a TGA-Q50 (TA instruments, Inc., New Castle, DE). The amount of samples used were between 10-20 mg and were placed into an alumina pan and heated from $25^{\circ} \mathrm{C}$ to $1000{ }^{\circ} \mathrm{C}$ at a rate of $10{ }^{\circ} \mathrm{C} / \mathrm{min}$ under air at a flow of $60 \mathrm{~mL} / \mathrm{min}$.

NMR analyses

${ }^{1} \mathrm{H}$ and ${ }^{13} \mathrm{C}$-NMR were conducted on a Bruker Avance 300 spectrometer. All data were collected from a $300 \mathrm{MHz}$ Bruker instrument using Xwin-NMR software. ${ }^{13} \mathrm{C}-\mathrm{NMR}$ spectra were collected at a $75.468 \mathrm{MHz}$ while $\mathrm{CDCl}_{3}$ was used as the solvent with TMS as the internal reference. ${ }^{13} \mathrm{C}$ NMR were conducted on a Bruker Avance $500 \mathrm{MHz}$ spectrometer with cryoprobe and Topspin software. All the ${ }^{1} \mathrm{H},{ }^{13} \mathrm{C}$, and ${ }^{29} \mathrm{Si}$ NMR analyses were done using DMSO (dimethylsulfoxide- $\mathrm{d}_{6}$ ) and/or $\mathrm{CDCl}_{3}$ (chloroform-d) as the solvent.

\section{Matrix Assisted Laser Desorption/ Time of Flight Spectrometry (MALDI-ToF)}

A Bruker Daltonics OmniFlex MALDI-TOF Mass Spectrometer was used with dithranol as the calibration matrix and $\mathrm{AgNO}_{3}$ as the ion source for the analyses. Samples were prepared by using 5 parts of matrix, 5 parts of samples and 1 part of $\mathrm{AgNO}_{3}$. The mixture was then blotted on the sample plate. The sample was observed at $55 \%$ laser power.

Direct insertion probe mass spectrometry (DIP-MS)

Direct Insertion Probe (DIP) experiments were conducted using a Shimadzu GCMS-QP2010 plus gas chromatograph mass spectrometer (serial no. C705044). The concentration of samples was 1 $\mathrm{mg} / \mathrm{mL}$ with spectrophotometric grade acetonitrile $\left(\mathrm{CH}_{3} \mathrm{CN}\right)$ as the solvent.

\section{Photophysical characterization}

\section{$\underline{\mathrm{UV} / \mathrm{Vis} \text { analysis }}$}

Steady state photophysical data for both oligomers and models were studied using spectrophotometric grade THF as the solvent. UV-vis experiments were carried out by using a Cary $60 \mathrm{UV} / \mathrm{Vis}$ from Agilent technologies for steady state absorption analyses. The concentration for both oligomers and models was $0.05-0.1 \mu \mathrm{M}$ in order to avoid any kind of self-absorption or quenching. For molar absorptivity calculations, absorption at different concentrations $(5,10,15,22$ $\mu \mathrm{M})$ were used to plot a concentration vs. absorbance graph in Origin software. The best fit slope of the line was used for the calculations at different $\lambda_{\max }$ as specified in the text.

\section{Photoluminescence analysis}

Fluorescence data were collected using a Fluorolog (model FL3-11) Jobin Yvon Horiba fluorimeter. FluorEssence software was used for the analyses of spectral properties. All the emission spectra were collected by exciting the compounds at $310 \mathrm{~nm}$ wavelength in THF. For the calculation of luminescence quantum yields we used comparison method where the standard used was anthracene in cyclohexane that has a quantum yield of 0.36. All the solutions were diluted such that they have an absorption up to 0.15 in order to avoid any excimer formation. Cuvettes used for the whole experiment had an optical path length of $1 \mathrm{~cm}$. For consistency, absorption and emission data were collected at the same time while the instruments were kept on until the experiment was completed. PLQY calculations were done using calculation table in an excel file. The following equation (1) was used for PLQY calculations: 


$$
\Phi(x)=\frac{\mathrm{A}_{\mathrm{s}}}{\mathrm{A}_{\mathrm{x}}} \times \frac{\mathrm{F}_{\mathrm{x}}}{\mathrm{F}_{\mathrm{s}}} \frac{n^{2} x}{n^{2}} \times \Phi(\mathrm{s})
$$

where, $\Phi(x)$ and $\Phi(s)$ are luminescence quantum yield for unknown and standard respectively. A is the absorption of samples at the excitation wavelength, $\mathrm{F}$ is the integrated emission obtained by using origin software, $\mathrm{n}$ is the refractive index of solvent (solution). Subscript $\mathrm{s}$ and $\mathrm{x}$ denote standard and samples respectively.

Femtosecond transient absorption measurements:

Femtosecond transient absorption measurements were carried out at the Center for Nanoscale Materials, Argonne National Laboratory. ${ }^{62}$ Briefly, a Spectra Physics Tsunami Ti: Sapphire, 75 $\mathrm{MHz}$ oscillator was used to seed a $5 \mathrm{KHz}$ Spectra-physics Spit-Fire Pro regenerative amplifier. $95 \%$ of the output from the amplifier is used to pump a TOPAS optical parametric amplifier, which is used to provide the pump beam in a Helios transient absorption setup (Ultrafast Systems Inc.). A pump beam of $370 \mathrm{~nm}$ was used for the measurements. The remaining $5 \%$ of the amplified output is focused onto a sapphire crystal to create a white light continuum that serves as the probe beam in our measurements (440 to $780 \mathrm{~nm}$ ). The pump beam was depolarized and chopped at 2.5 $\mathrm{kHz}$ and both pump and probe beams were overlapped in the sample for carrying out magic angle transient absorption measurements. All the data analysis was carried out using Surface Xplorer from Ultrafast Systems. For anisotropy measurements, samples are excited with vertically polarized $370 \mathrm{~nm}$ pump and probe beam is split as vertical and horizontal polarization after it is passed from the sample and detected with two matched photodiodes. Vertically polarized probe beam monitors $\Delta A_{\|}$while horizontally polarized probe beam monitors $\Delta A_{\perp}$ and corresponding anisotropy is determined as a function of time and wavelength using eq. (2).

$$
r(t)=\frac{\left(\Delta \mathrm{A}_{\|}-\Delta \mathrm{A}_{\perp}\right)}{\left(\Delta \mathrm{A}_{\|}+2 \Delta \mathrm{A}_{\perp}\right)}
$$

During the transient absorption measurements, no degradation of the sample was detected as the traces overlapped after each repetition and the absorption spectrum did not change before and after the measurement.

Fluorescence Lifetime Measurements: Time-resolved fluorescence measurements were carried out with time-correlated single photon counting technique using Edinburgh F900 spectrofluorimeter. $373 \mathrm{~nm}$ diode (PicoQuant) was used as the excitation source and the resulting fluorescence was detected at corresponding fluorescence maximum wavelengths using a Hamamatsu R7158 photomultiplier tube. Aluminum foil was used as scatter to obtain instrument response function. The decay traces were deconvoluted and fitted with multi-exponential function to determine fluorescence lifetimes.

\section{Synthesis}

Synthesis of divinyl silsesquioxane Cage

$2.40 \mathrm{~g}(2.32 \mathrm{mmol})$ of OPS (octaphenylsilsesquioxane) were put in a $500 \mathrm{~mL}$ round bottom flask. $808 \mathrm{mg}$ of vinyltriethoxysilane $(896 \mu \mathrm{L})$ were then added to the flask following the addition of $200 \mathrm{~mL}$ dichloromethane, $250 \mu \mathrm{L}$ TBAF (tetra-butylammonium fluoride), and $229 \mu \mathrm{L}$ of DI water in the flask along with a magnetic stirrer. The solution was kept stirring at room temperature for 48 hours. After 48 hours, $0.1 \mathrm{~g} \mathrm{CaCl}_{2}$ were added as fluoride quenching agent. Then the solution was stirred for an additional 24 hours. After 24 hours of final stirring the insoluble part were 
filtered through Celite. The liquid was then evaporated on a rotary evaporator to give an oily liquid. The liquid was then reprecipitated in $200 \mathrm{~mL}$ of methanol to give a solid white powder. The powder was then filtered, and vacuum dried to the desired product. The yield of the reaction was $76.79 \%$. ${ }^{1} \mathrm{H}$ NMR $\left(\mathrm{CDCl}_{3}, \delta \mathrm{ppm}\right)$ : 6.5-7.6 (br, Ar-H), 5.6-6.2 (br, $\left.-\mathrm{CH}=\mathrm{CH}_{2}\right)$. FTIR $\left(\mathrm{cm}^{-1}\right): 3100-3000\left(v_{\mathrm{C}-\mathrm{H}}\right), 1500$ $\left(v_{\mathrm{C}=\mathrm{C},}, \mathrm{Ar}\right.$ ring $), 1050 \quad\left(v_{\mathrm{Si}-\mathrm{O}}\right) . \quad$ MALDI-ToF: $\mathrm{m} / \mathrm{z} \quad\left(\mathrm{Ag}^{+}\right) \quad 1149\left[\mathrm{Si}_{10} \mathrm{O}_{15}\left(\mathrm{C}_{2} \mathrm{H}_{3}\right)_{5}\left(\mathrm{C}_{6} \mathrm{H}_{5}\right)_{5}\right]$, 1199[ $\left.\mathrm{Si}_{10} \mathrm{O}_{15}\left(\mathrm{C}_{2} \mathrm{H}_{3}\right)_{4}\left(\mathrm{C}_{6} \mathrm{H}_{5}\right)_{6}\right], \quad 1249\left[\mathrm{Si}_{10} \mathrm{O}_{15}\left(\mathrm{C}_{2} \mathrm{H}_{3}\right)_{3}\left(\mathrm{C}_{6} \mathrm{H}_{5}\right)_{7}\right], \quad 1299\left[\mathrm{Si}_{10} \mathrm{O}_{15}\left(\mathrm{C}_{2} \mathrm{H}_{3}\right)_{2}\left(\mathrm{C}_{6} \mathrm{H}_{5}\right)_{8}\right]$, 1350[ $\left.\mathrm{Si}_{10} \mathrm{O}_{15}\left(\mathrm{C}_{2} \mathrm{H}_{3}\right)_{1}\left(\mathrm{C}_{6} \mathrm{H}_{5}\right)_{9}\right], \quad 1458\left[\mathrm{Si}_{12} \mathrm{O}_{18}\left(\mathrm{C}_{2} \mathrm{H}_{3}\right)_{4}\left(\mathrm{C}_{6} \mathrm{H}_{5}\right)_{8}\right], \quad 1508\left[\mathrm{Si}_{12} \mathrm{O}_{18}\left(\mathrm{C}_{2} \mathrm{H}_{3}\right)_{3}\left(\mathrm{C}_{6} \mathrm{H}_{5}\right)_{9}\right]$, $1558\left[\mathrm{Si}_{12} \mathrm{O}_{18}\left(\mathrm{C}_{2} \mathrm{H}_{3}\right)_{2}\left(\mathrm{C}_{6} \mathrm{H}_{5}\right)_{10}\right], 1608\left[\mathrm{Si}_{12} \mathrm{O}_{18}\left(\mathrm{C}_{2} \mathrm{H}_{3}\right)_{1}\left(\mathrm{C}_{6} \mathrm{H}_{5}\right)_{11}\right]$. GPC: $\mathrm{M}_{\mathrm{n}}=1.5 \mathrm{kDa}, \mathrm{M}_{\mathrm{w}}=1.6 \mathrm{kDa}, \mathrm{PDI}=$ 1.07.

Then $2 \mathrm{~g}$ of synthesized mixed vinyl cages was dissolved in $20 \mathrm{~mL}$ of acetonitrile. The mixture was stirred overnight. Parts of the mixture remained undissolved. The dissolved portion was filtered and concentrated by rotary evaporator. The resulting solution was then re-precipitated using $50 \mathrm{~mL}$ of methanol, filtered and resulted in $1.3 \mathrm{~g}$ of white powdered material. MALDI-ToF analysis confirmed the removal of most mono-vinyl cages and therefore enriched in divinyl and higher vinyl substituents with $65 \%$ of yield. ${ }^{1} \mathrm{H}$ NMR $\left(\mathrm{CDCl}_{3}, \delta \mathrm{ppm}\right)$ : 6.5-7.6 (br, Ar-H), 5.6-6.2 $\left(\mathrm{br},-\mathrm{CH}=\mathrm{CH}_{2}\right)$. FTIR $\left(\mathrm{cm}^{-1}\right): 3100-3000\left(v_{\mathrm{C}-\mathrm{H}}\right), 1500\left(v_{\mathrm{C}=\mathrm{C}}, \mathrm{Ar}\right.$ ring $), 1050\left(v_{\mathrm{Si}-\mathrm{O}}\right)$. MALDI-ToF: m/z $\left(\mathrm{Ag}^{+}\right) 1149 \quad\left[\mathrm{Si}_{10} \mathrm{O}_{15}\left(\mathrm{C}_{2} \mathrm{H}_{3}\right)_{5}\left(\mathrm{C}_{6} \mathrm{H}_{5}\right)_{5}\right], \quad 1199\left[\mathrm{Si}_{10} \mathrm{O}_{15}\left(\mathrm{C}_{2} \mathrm{H}_{3}\right)_{4}\left(\mathrm{C}_{6} \mathrm{H}_{5}\right)_{6}\right], \quad 1249 \quad\left[\mathrm{Si}_{10} \mathrm{O}_{15}\left(\mathrm{C}_{2} \mathrm{H}_{3}\right)_{3}\left(\mathrm{C}_{6} \mathrm{H}_{5}\right)_{7}\right]$, $1299\left[\mathrm{Si}_{10} \mathrm{O}_{15}\left(\mathrm{C}_{2} \mathrm{H}_{3}\right)_{2}\left(\mathrm{C}_{6} \mathrm{H}_{5}\right)_{8}\right], \quad 1458\left[\mathrm{Si}_{12} \mathrm{O}_{18}\left(\mathrm{C}_{2} \mathrm{H}_{3}\right)_{4}\left(\mathrm{C}_{6} \mathrm{H}_{5}\right)_{8}\right], \quad 1508\left[\mathrm{Si}_{12} \mathrm{O}_{18}\left(\mathrm{C}_{2} \mathrm{H}_{3}\right)_{3}\left(\mathrm{C}_{6} \mathrm{H}_{5}\right)_{9}\right]$, $1558\left[\mathrm{Si}_{12} \mathrm{O}_{18}\left(\mathrm{C}_{2} \mathrm{H}_{3}\right)_{2}\left(\mathrm{C}_{6} \mathrm{H}_{5}\right)_{10}\right]$. GPC: $\mathrm{M}_{\mathrm{n}}=1.4 \mathrm{kDa}, \mathrm{M}_{\mathrm{w}}=1.5 \mathrm{kDa}, \mathrm{PDI}=1.04$. TGA: d5\% $400{ }^{\circ} \mathrm{C}$, Actual CY 52.1\%, Estimated CY (divinyl): 51.4\%.

\section{Synthesis of oligomers (general procedure)}

$500 \mathrm{mg}$ (3.845 mmol) of synthesized divinyloctaphenyl $\mathrm{T}_{10 / 12}$ cage were put in a dried, argon purged $50 \mathrm{~mL}$ Schlenk flask. After that $0.084 \mathrm{mmol}$ of organic cross linkers, $19 \mathrm{mg}(0.042 \mathrm{mmol})$ of $\mathrm{Pd}\left[\mathrm{P}-(\mathrm{t}-\mathrm{Bu})_{3}\right]_{2}, 18 \mathrm{mg}(0.02 \mathrm{mmol})$ of $\mathrm{Pd}_{2} \mathrm{dba}_{3}$ were added to the flask. $5 \mathrm{~mL}$ of 1,4-dioxane were used to dissolve the materials. Then $0.45 \mathrm{~mL}(2.175 \mathrm{mmol})$ of $\mathrm{NCy}_{2} \mathrm{Me}$ were added as base. The whole reaction was done under argon condition. The reaction was kept on stirring for 72 hours at room temperature. After 72 hours, the reaction mixture was then filtered using Celite to separate out catalysts involved in the reaction. The celite was washed with dichloromethane during filtration. The liquid was then collected in a $250 \mathrm{~mL}$ round bottom flask and the solvent was evaporated using a rotary evaporator to get an oil like substance. The oil was then reprecipitated using $200 \mathrm{~mL}$ of methanol and then filtered to get the solid compounds. A plug column with silica was run to purify the products, with 9:1 ratio of hexane to ethyl acetate as the eluent. After the column, the compound was re-precipitated with $200 \mathrm{~mL}$ methanol and then filtered using a filtering funnel to get the purified product. BT oligomer: ${ }^{1} \mathrm{H} \mathrm{NMR}\left(\mathrm{CDCl}_{3}, \delta \mathrm{ppm}\right)$ : 7.6-8.0 (br, $\left.\mathrm{Ar}-\mathrm{H}\right), 5.9$ $\left(\mathrm{br},-\mathrm{CH}=\mathrm{CH}_{2}\right)$. FTIR $\left(\mathrm{cm}^{-1}\right)$ : 3000-2900 $\left(v_{\text {Ar C-H }}\right), 1650\left(v_{\mathrm{C}=\mathrm{N}}\right), 1500\left(v_{\mathrm{C}=\mathrm{C}}, \mathrm{Ar}\right.$ ring $), 1120\left(v_{\mathrm{Si}-\mathrm{O}-\mathrm{Si}}\right)$, $1010\left(v_{\mathrm{Si}-\mathrm{O}-\mathrm{Si}}\right), 700\left(v_{\mathrm{N}-\mathrm{S}}\right)$. GPC: $\mathrm{M}_{\mathrm{n}}=3786 \mathrm{Da}, \mathrm{M}_{\mathrm{w}}=5410 \mathrm{Da}, \mathrm{PDI}=1.43$. PQ oligomer: ${ }^{1} \mathrm{H} \mathrm{NMR}$ $\left(\mathrm{CDCl}_{3}, \delta \mathrm{ppm}\right)$ : 7.6-7.9 (br, Ar-H), 5.9 (br, $\left.-\mathrm{CH}=\mathrm{CH}_{2}\right)$. FTIR $\left(\mathrm{cm}^{-1}\right)$ : 3000-2800 (v Ar c-H $), 1610$ $\left(v_{\mathrm{C}=\mathrm{O}}\right), 1500\left(v_{\mathrm{C}=\mathrm{C}}, \mathrm{Ar}\right.$ ring $), 1100\left(v_{\mathrm{Si}-\mathrm{O}-\mathrm{Si}}\right), 1030\left(v_{\mathrm{Si}-\mathrm{O}-\mathrm{Si}}\right) \mathrm{GPC}: \mathrm{M}_{\mathrm{n}}=2836$ Da, $\mathrm{M}_{\mathrm{w}}=3934 \mathrm{Da}, \mathrm{PDI}=$ 1.39. EC oligomer: ${ }^{1} \mathrm{H}$ NMR $\left(\mathrm{CDCl}_{3}, \delta \mathrm{ppm}\right)$ : 7.6-7.8 (br, Ar-H), $6.0\left(\mathrm{br},-\mathrm{CH}=\mathrm{CH}_{2}\right), 4.3(\mathrm{~s},-\mathrm{N}-$ $\left.\mathrm{C}_{2} \mathrm{H}_{5}\right)$. FTIR $\left(\mathrm{cm}^{-1}\right): 3070\left(v_{\mathrm{Ar} \mathrm{C}-\mathrm{H}}\right), 2880\left(v_{\mathrm{C}-\mathrm{H}}\right), 1600\left(v_{\mathrm{N}-\mathrm{H}}\right.$ bend $), 1490-1520\left(v_{\mathrm{C}=\mathrm{C}}\right.$, Ar ring $), 1100$ $\left(v_{\text {Si-O-Si }}\right)$ GPC: $\mathrm{M}_{\mathrm{n}}=4967 \mathrm{Da}, \mathrm{M}_{\mathrm{w}}=6542 \mathrm{Da}, \mathrm{PDI}=1.32$. PC oligomer: ${ }^{1} \mathrm{H} \mathrm{NMR}\left(\mathrm{CDCl}_{3}, \delta \mathrm{ppm}\right)$ : 7.6-7.8 (br, Ar-H), $6.0\left(\mathrm{br},-\mathrm{CH}=\mathrm{CH}_{2}\right)$. FTIR $\left(\mathrm{cm}^{-1}\right)$ : $3070\left(v_{\mathrm{Ar}-\mathrm{H}}\right), 1590\left(v_{\mathrm{N}-\mathrm{H}}\right.$ bend $), 1440\left(v_{\mathrm{C}=\mathrm{C},} \mathrm{Ar}\right.$ ring), $1100\left(v_{\text {Si-O-Si }}\right)$ GPC: $\mathrm{M}_{\mathrm{n}}=5782 \mathrm{Da}, \mathrm{M}_{\mathrm{w}}=7424 \mathrm{Da}, \mathrm{PDI}=1.28$. Additional characterization 
data given in the text and supporting information.

\section{Synthesis of bis-tri-isopropoxysilyl model compounds (general procedure)}

In a $50 \mathrm{~mL}$ dry, argon purged Schlenk flask, $0.295 \mathrm{mmol}$ dibromo cross-linkers were added along with $4 \mathrm{~mL} \mathrm{1,4-dioxane.} \mathrm{After} \mathrm{that} 10 \mathrm{mg}(0.02 \mathrm{mmol})$ of $\mathrm{Pd}\left[\mathrm{P}-(\mathrm{t}-\mathrm{Bu})_{3}\right]_{2}, 8 \mathrm{mg}(0.01 \mathrm{mmol})$ of $\mathrm{Pd}_{2} \mathrm{dba}_{3}$ were added along with $0.5 \mathrm{~mL}$ of distilled vinyl-triisopropoxysilane and $0.3 \mathrm{~mL}$ (1.4 mmol) $\mathrm{NCy}_{2} \mathrm{Me}$. The reaction was kept on stirring with a magnetic stir bar at room temperature for 72 hours. After 72 hours, the solution was filtered using Celite, washing with dichloromethane. The filtrate was then poured into a $250 \mathrm{~mL}$ round bottom flask and the solvent was evaporated using rotary evaporation. The oily solid compound was then collected and kept under argon to prevent further modifications. The compounds were kept under argon and stored long-term in the fridge at $2{ }^{\circ} \mathrm{C}$. BT model compound: ${ }^{1} \mathrm{H} \mathrm{NMR}\left(\mathrm{CDCl}_{3}, \delta \mathrm{ppm}\right): 7.5(\mathrm{~s}, \mathrm{Ar}-\mathrm{H}), 6.8\left(\mathrm{~d},-\mathrm{CH}=\mathrm{CH}_{2}\right)$, $3.8\left(\mathrm{~m},-\mathrm{O}-\mathrm{C}_{3} \mathrm{H}_{7}\right), 1.2\left(\mathrm{~m},-\mathrm{O}-\mathrm{C}_{3} \mathrm{H}_{7}\right)$. DIP-MS: $\mathrm{M}^{+}=595 \mathrm{~m} / \mathrm{z}$. FTIR $\left(\mathrm{cm}^{-1}\right): 3000-2900\left(v_{\mathrm{Ar} \mathrm{c}-\mathrm{H}}\right)$, $1650\left(v_{\mathrm{C}=\mathrm{N}}\right), 1500\left(v_{\mathrm{C}=\mathrm{C}}\right.$, Ar ring $), 1110\left(v_{\mathrm{C}-\mathrm{O}}\right), 1030\left(v_{\mathrm{Si}-\mathrm{O}}\right) \mathrm{GPC}: \mathrm{M}_{\mathrm{n}}=1378 \mathrm{Da}, \mathrm{M}_{\mathrm{w}}=1405 \mathrm{Da}, \mathrm{PDI}=$ 1.02. PQ model compound: ${ }^{1} \mathrm{H}$ NMR $\left(\mathrm{CDCl}_{3}, \delta \mathrm{ppm}\right): 8.1(\mathrm{~s}, \mathrm{Ar}-\mathrm{H}), 7.8(\mathrm{~d}, \mathrm{Ar}-\mathrm{H}), 6.9(\mathrm{~d}$, $\left.\mathrm{CH}=\mathrm{CH}_{2}\right), 5.6\left(\mathrm{~d},-\mathrm{CH}=\mathrm{CH}_{2}\right), 3.8\left(\mathrm{~m},-\mathrm{O}-\mathrm{C}_{3} \mathrm{H}_{7}\right), 1.2\left(\mathrm{~m},-\mathrm{O}-\mathrm{C}_{3} \mathrm{H}_{7}\right)$. DIP-MS: $\mathrm{M}^{+}=670 \mathrm{~m} / \mathrm{z}$. FTIR $\left(\mathrm{cm}^{-1}\right)$ : 3000-2800 ( $\left.v_{\text {Ar C-H }}\right), 1660\left(v_{\mathrm{C}=\mathrm{O}}\right), 1500\left(v_{\mathrm{C}=\mathrm{C}}\right.$, Ar ring $), 1110\left(v_{\mathrm{C}-\mathrm{O}}\right), 1030\left(v_{\mathrm{Si}-\mathrm{O}}\right)$ GPC: $\mathrm{M}_{\mathrm{n}}=$ $1363 \mathrm{Da}, \mathrm{M}_{\mathrm{w}}=1418 \mathrm{Da}, \mathrm{PDI}=1.04$. EC model compound: ${ }^{1} \mathrm{H} \mathrm{NMR}\left(\mathrm{CDCl}_{3}, \delta \mathrm{ppm}\right): 8.2(\mathrm{~s}, \mathrm{Ar}-$ $\mathrm{H}), 8.1(\mathrm{~s}, \mathrm{Ar}-\mathrm{H}), 7.6(\mathrm{~m}, \mathrm{Ar}-\mathrm{H}), 6.9\left(\mathrm{~m},-\mathrm{CH}=\mathrm{CH}_{2}\right), 5.6\left(\mathrm{~d},-\mathrm{CH}=\mathrm{CH}_{2}\right), 4.5\left(\mathrm{~m},-\mathrm{N}-\mathrm{C}_{2} \mathrm{H}_{5}\right), 3.8(\mathrm{~m}$, $\left.-\mathrm{O}-\mathrm{C}_{3} \mathrm{H}_{7}\right), 1.2\left(\mathrm{~m},-\mathrm{O}-\mathrm{C}_{3} \mathrm{H}_{7}\right)$. DIP-MS: $\mathrm{M}^{+}=655 \mathrm{~m} / \mathrm{z}$. FTIR $\left(\mathrm{cm}^{-1}\right): 3000-2800\left(v_{\text {Ar c-H }}\right), 1600\left(v_{\mathrm{N}-}\right.$ н bend), 1490 ( $v_{\mathrm{C}=\mathrm{C}}$, Ar ring), $1110\left(v_{\mathrm{C}-\mathrm{O}}\right), 1020\left(v_{\mathrm{Si}-\mathrm{O}}\right)$ GPC: $\mathrm{M}_{\mathrm{n}}=1506 \mathrm{Da}, \mathrm{M}_{\mathrm{w}}=1522 \mathrm{Da}, \mathrm{PDI}=$ 1.01. PC model compound: ${ }^{1} \mathrm{H}$ NMR $\left(\mathrm{CDCl}_{3}, \delta \mathrm{ppm}\right): 8.3(\mathrm{~s}, \mathrm{Ar}-\mathrm{H}), 8.2(\mathrm{~s}, \mathrm{Ar}-\mathrm{H}), 7.6$ (br, Ar-H), $6.9(\mathrm{~m}, \mathrm{Ar}-\mathrm{H}), 5.6\left(\mathrm{~d},-\mathrm{CH}=\mathrm{CH}_{2}\right), 3.8\left(\mathrm{~m},-\mathrm{O}-\mathrm{C}_{3} \mathrm{H}_{7}\right), 1.2\left(\mathrm{~m},-\mathrm{O}-\mathrm{C}_{3} \mathrm{H}_{7}\right)$. DIP-MS: $\mathrm{M}^{+}=703 \mathrm{~m} / \mathrm{z}$. FTIR $\left(\mathrm{cm}^{-1}\right)$ : 3070-2780 ( $\left.v_{\text {Ar C-H }}\right), 1590\left(v_{\mathrm{N}-\mathrm{H}}\right.$ bend $), 1440\left(v_{\mathrm{C}=\mathrm{C}}\right.$, Ar ring $), 1110\left(v_{\mathrm{C}-\mathrm{O}}\right), 1030\left(v_{\mathrm{Si}-\mathrm{O}}\right)$ GPC: $\mathrm{M}_{\mathrm{n}}=1552 \mathrm{Da}, \mathrm{M}_{\mathrm{w}}=1568 \mathrm{Da}, \mathrm{PDI}=1.01$.

\section{Results and discussion}

In the present work, we have synthesized vinyl-phenyl $\mathrm{T}_{10}$ and $\mathrm{T}_{12} \mathrm{SQs}$. The reaction results in a mixture of $\mathrm{T}_{10}$ and $\mathrm{T}_{12}$ cages with vinyl groups ranging from 0 to 5 , in which the lower substitutions can be separated by selective precipitation methods. The vinyl groups attached to our cage system are used to combine an organic dibromo-aromatic cross-linker, which gives conjugated organo-SQ oligomeric material by Heck cross-coupling reactions (Scheme 1). To analyze the influence of SQ cage systems on the overall photophysical properties, we have also synthesized bis-tri-alkoxysilyl linker compounds (model compounds), to isolate the linker in a similar environment, but which do not offer phenyl or cage structures. Limited analyses have been done to decipher the photophysical properties such as excitation energy transfer or hopping in small oligomeric mixed vinyl SQ cage systems using the organic cross-linkers (BT, PQ, EC and, PC). Spectroscopic techniques such as UV/Vis and fluorescence were used to gain a base set of photophysical properties of these BoC systems including the propensity for charge transfer through the materials (Scheme 1). Whereas charge transfer and excited state interactions were investigated using transient absorption, anisotropy, and fluorescence single photon counting methods. The following sections will detail the synthesis and photophysical spectroscopic analysis of these systems.

\section{Phenyl/vinyl silsesquioxane cages}


Reaction Scheme 1 shows the generation of mixed phenyl/vinyl cages with a statistical favorability for divinyl functionality. Matrix Assisted Laser Desorption Ionization-Time of Flight (MALDI-TOF) analysis shows that the average functionality is $\sim$ divinyl-octaphenyl cages (Figure 1a). In the initial reaction there is still substantial mono-vinyl substitution present, which must be removed to increase the propensity for higher molecular weight oligomers without the monovinyls end capping prematurely. Mono-vinyl cages were separated out using selective precipitation methods in acetonitrile (ACN), with the higher vinyl substitutions remaining in solution. MALDIToF showed that separation was effective by decreases in the mono-vinyl peak at $1348 \mathrm{~m} / \mathrm{z}$ relative to those of (vinyl) $)_{2,3,4}$ cages (Figure 1b).

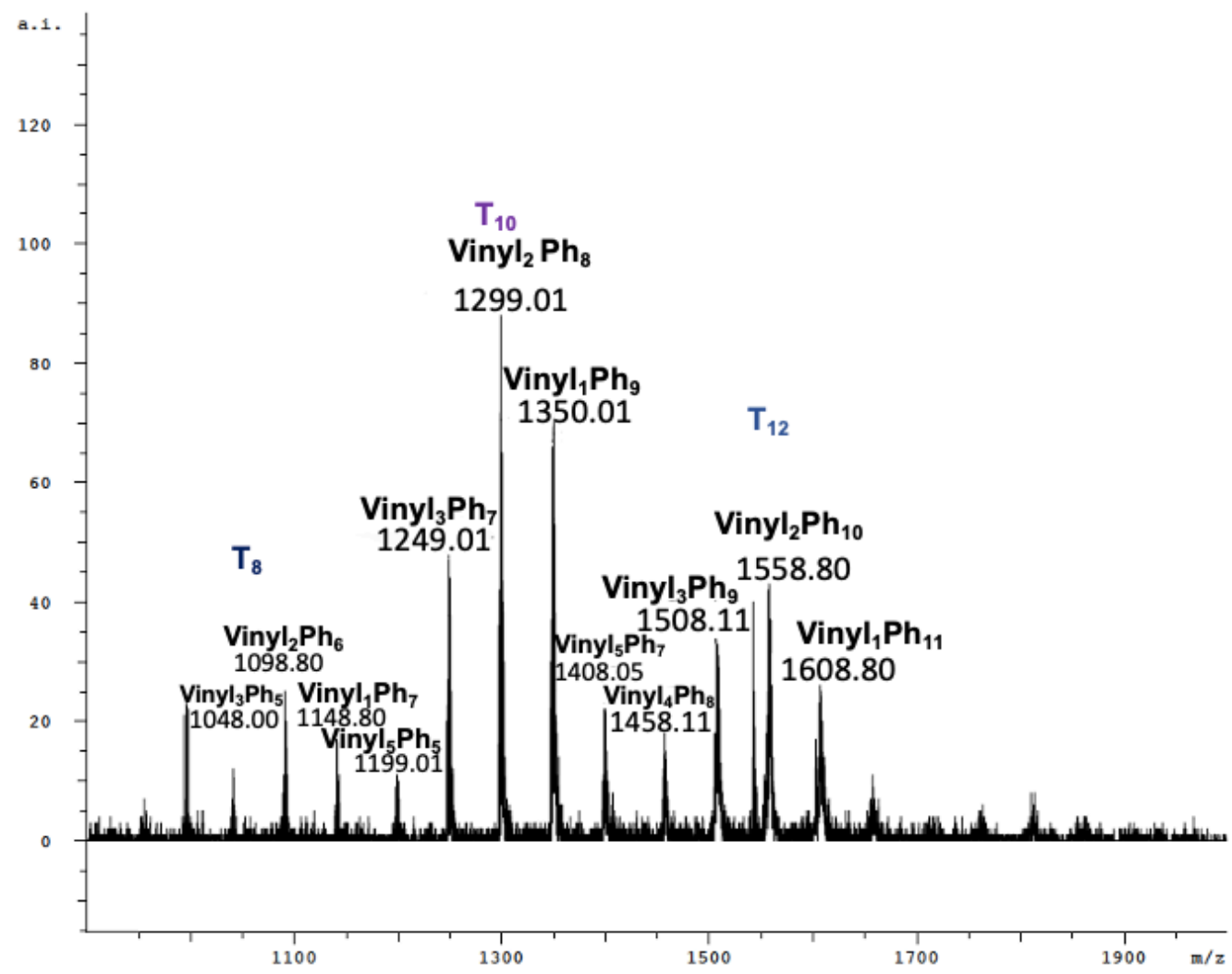




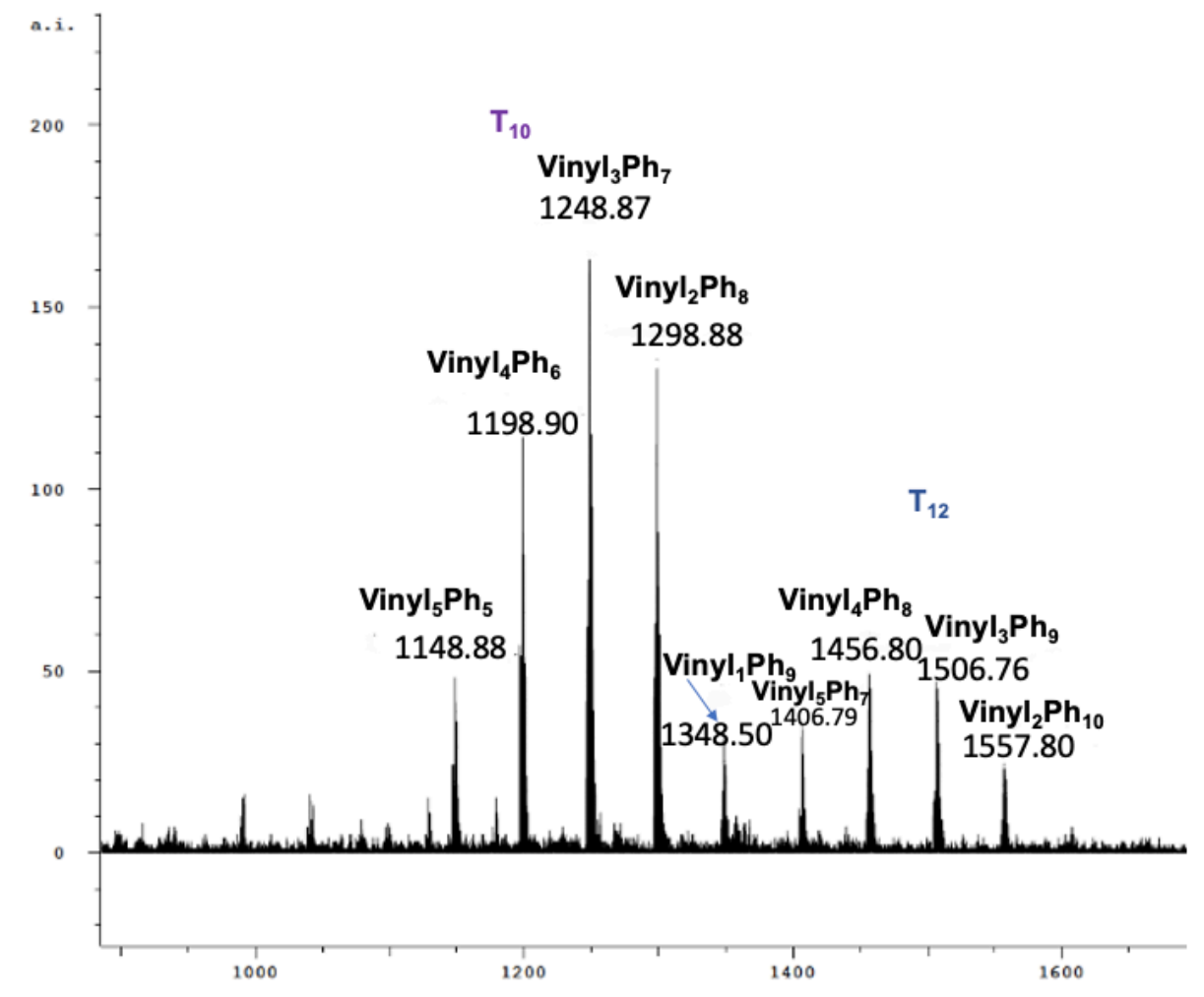

Figure 1. (a) MALDI-ToF analysis of mixed vinyl/phenyl SQs synthesized using fluoride catalyzed rearrangement (Ag+ ions), (b) MALDI-ToF of enriched multivinyl-phenylSQs showing decrease in monovinyl substitution.

Synthesized mixed phenyl/vinyl cage systems show good thermal stability as per Thermal Gravimetric Analysis (TGA) analysis, with $\mathrm{d}_{5 \%}$ of $400{ }^{\circ} \mathrm{C}$ and ceramic yield (CY) of $52.1 \%$. Ceramic yield $(\mathrm{CY})$ is the amount of silica $\left(\mathrm{SiO}_{2}\right)$ remaining after burning off organics in air and can be used to verify molecular composition. The obtained CY is between the theoretical value of $51.4 \%$ for divinyloctaphenyl and $52.6 \%$ for trivinylheptaphenyl, with a value closer to the latter being corroborated by the MALDI-ToF results. The amount of mono-vinyl $(1348.50 \mathrm{~m} / \mathrm{z}$, Figure 1 ) is low at $18 \%$ peak intensity of the highest peak. ${ }^{1} \mathrm{H}$ NMR analysis shows two distinct regions, a broad signal ranging from $\sim 7-7.9 \mathrm{ppm}$ for phenyl protons and $\sim 5.8-6.2 \mathrm{ppm}$ for vinylic protons, with the breadth due to variations in the positions of vinyl groups relative to one another. The GPC chromatogram of mixed SQ cages gave a PDI of 1.07 and a retention time from 31 to $32.5 \mathrm{~min}$, which is expected for mixed cages.

\section{General Characterization of Oligomers and Models}

Gel permeation chromatography gives us the extent of oligomerization of the oligomer chains, molecular weight distribution, and polydispersity index. ${ }^{63-67}$ Toluene was used as an internal calibration standard to see if the GPC spectrum itself has drifted and allows for a point of correction. We have run a set of polystyrene standards and developed a calibration file for analyzing the $\mathrm{M}_{\mathrm{n}}$ (number average $\mathrm{MW}$ ), $\mathrm{M}_{\mathrm{w}}$ (weight average $\mathrm{MW}$ ) and PDI (polydispersity index). The GPC result confirms the presence of oligomeric species. Note that the MW for these oligomers is only a lower limit estimate since their structures would be partially branched due to some cages containing more than two vinyl substitutions. The calculated data for each of the oligomers are given in Table 1. The number of repeat units is calculated based on the $\mathrm{M}_{\mathrm{n}}$ value. Among these structures the carbazoles average six repeat units, while the BT and PQ oligomers 
are four and three units respectively. PDI values show the breadth in molecular weight distributions, which is greatest for the BT oligomer at 1.43. However, PDI ranging from 1.28-1.43 indicates relatively narrow distribution of molecular weights. These values also indicate the heterogeneity in cross-linking is lowest in PC oligomer and highest in BT oligomer.

Table 1. GPC analysis of synthesized BoC oligomers.

\begin{tabular}{|c|c|c|c|c|}
\hline Cross linker & $\begin{array}{c}\mathbf{M}_{\mathbf{n}} \\
\text { (Daltons) }\end{array}$ & $\begin{array}{c}\mathbf{M}_{\mathbf{w}} \\
\text { (Daltons) }\end{array}$ & PDI & $\begin{array}{c}\text { Number of repeat } \\
\text { units from } \mathbf{M}_{\mathbf{n}}\end{array}$ \\
\hline Benzothiadiazole (BT) & 3786 & 5410 & 1.43 & 4 \\
\hline $\begin{array}{c}\text { Phenanthrenequinone } \\
\text { (PQ) }\end{array}$ & 2836 & 3934 & 1.39 & 6 \\
\hline $\begin{array}{c}\text { Ethyl-carbazole (EC) } \\
\text { Phenyl-carbazole (PC) }\end{array}$ & 5967 & 6542 & 1.32 & 6 \\
\hline
\end{tabular}

Thermal stability determination of the oligomers was conducted using TGA. Since the compounds contain mostly $\mathrm{Si}-\mathrm{O}$ bonds and aromatic hydrocarbons it shows excellent thermal stability of greater than $450{ }^{\circ} \mathrm{C}$ in all cases. Table 2 shows the $\mathrm{d}_{5 \%}$ and ceramic yields of the oligomers. The theoretical CY for the BT oligomer (if it contains only $\mathrm{T}_{10}$ and only 2 cross-links) is $44 \%$, so $\sim 4 \%$ higher than expected, this is due to the presence of some larger cage systems and varying cross-link density on each cage, which limits the overall organic content. This also suggests that the end units are more likely cages as opposed to cross-linkers. So, despite removing a large number of mono-vinyl cages, end capping is still prevalent. The advantages of using SQ systems is to provide additional thermal and photo stability as well as to improve the absorption coefficient of the materials. However, it shows limited propensity towards forming structures with high molecular weights.

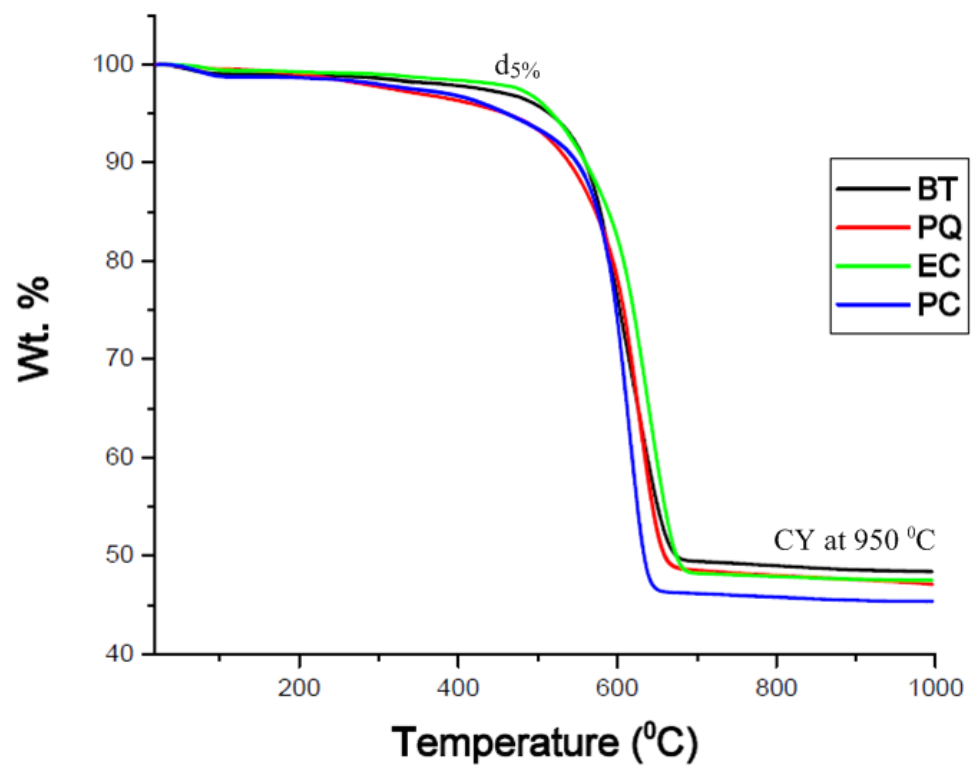


Figure 5. TGA plot for Benzothiadiazole (BT), Phenanthrenequinone (PQ), Ethyl-carbazole (EC) and Phenylcarbazole (PC) oligomer respectively

Table 2. TGA analysis of synthesized BoC oligomers.

\begin{tabular}{|l|c|c|c|}
\hline Cross linker & $\mathbf{d}_{\mathbf{5} \%},{ }^{\circ} \mathbf{C}$ & Ceramic yield, \% & $\begin{array}{c}\text { Theoretical } \\
\text { ceramic yield, \% }\end{array}$ \\
\hline Benzothiadiazole (BT) & 516 & 48.47 & 44.34 \\
\hline Phenanthrenequinone (PQ) & 460 & 47.31 & 42.10 \\
\hline Ethyl Carbazole (EC) & 518 & 47.54 & 42.48 \\
\hline Phenyl Carbazole (PC) & 461 & 45.37 & 41.09 \\
\hline
\end{tabular}

FTIR analyses of the oligomers shows a sharp peak at $1050 \mathrm{~cm}^{-1}$, which is representative of an $\mathrm{Si}-\mathrm{O}$ stretch. This stretch is so strong, that the organic peaks from the linkers and cage corners are not easily visible. FTIR are given in Figures S10, 12, 14, 16).

Model compounds for spectroscopic comparisons have been synthesized by the same reaction strategy; however, the mixed vinyl cages were replaced by tri(isopropoxy)vinylsilane. This alkoxysilane with isopropoxy groups was used to limit premature oligomerization reactions by hydrolysis. Unlike oligomer materials, model compounds did not have molecular weight distributions from GPC analysis, rather each of them has a sharp single peak (See SI) indicating monodispersity. FTIR analyses of model compounds showed a prominent $\mathrm{C}-\mathrm{H}$ stretch from the phenylic cross-linkers along with other vibrational stretches. In all model compounds Si-O stretch at $1020-1030 \mathrm{~cm}^{-1}$ were observed along with $\mathrm{C}-\mathrm{H}$ vibrations at 2800-3000 from phenyl groups of linkers. Since they are monomeric units, the phenyl bands are dominant along with Si-O stretches, contrasting the oligomers. Phenyl and vinyl $\mathrm{C}=\mathrm{C}$ stretches were also found at $\sim 1500 \mathrm{~cm}^{-1}$. For BT $\mathrm{C}=\mathrm{N}$ stretching at $1650 \mathrm{~cm}^{-1}$ and $\mathrm{N}-\mathrm{S}$ vibrational peak at $700 \mathrm{~cm}^{-1}$ were observed. In PQ model, characteristic $\mathrm{C}=\mathrm{O}$ stretches at $1720 \mathrm{~cm}^{-1}$ along with the other bands were observed. $\mathrm{N}-\mathrm{H}$ bends for EC and PC model were found to be at 1600 and $1590 \mathrm{~cm}^{-1}$ respectively. In EC model, C-H vibrational bands were noticed from $2800-3000 \mathrm{~cm}^{-1}$ where in PC model it showed up from 2780$3070 \mathrm{~cm}^{-1}$. The intensity in that region is higher in the PC model, suggesting the presence of a phenyl group compared to the EC model where that group is ethyl. Direct Insertion Probe (DIP) Mass spectrometry was used to verify the molecular weights and fragmentation of each of the model compounds (Figures S25-S28). Detailed characterization data including FTIR, GPC, and ${ }^{1} \mathrm{H}-\mathrm{NMR}$ are given in the supporting information.

\section{Photophysical Analysis}

\section{Steady-state spectroscopy}

The absorption and emission spectra for oligomers and models are shown in Figure 6 . All these systems show considerable overlaps of emission and absorption with minor shifts in emissions. PLQY of model compounds were higher than their corresponding oligomers (PQ as an exception), meaning that in oligomers photons tend to be quenched from radiative process, and rather get transferred or migrated through the system by other non-radiative pathways. The overlap in absorption and emission spectra for all compounds shows a good indication of the formation of homo-FRET/energy migration-FRET systems, where absorption of the emission occurs in the same fluorophore (i.e. self-absorption or chromophore-chromophore through space interactions) ${ }^{68-70}$ Homo-FRET doesn't show the typical quenching of fluorescence as found in 
traditional FRET or hetero-FRET as energy flows through the same system. Here, the same molecule acts both as donor and acceptor. Efficient homo-FRET systems have very small Stoke's shift between excitation and emission spectra. ${ }^{71,72} \mathrm{We}$ see negligible changes in emission and absorption spectra between most of the oligomers and models, suggesting that with these crosslinkers as opposed to those used previously. ${ }^{55,73,74}$ The results indicate fewer strong interactions are taking place between the phenyl cages and the linkers. This could be due to the higher proportion of $\mathrm{T}_{10}$ cage sizes in this system which show less ability to form excimers, ${ }^{75}$ or due to the spatial overlap between the linkers and cage phenyl systems, both of which have been observed to result in spectral red shifts in the oligomeric compounds over models. Further analysis is undertaken to understand the small changes in spectra using time-resolved fluorescence and femtosecond transient absorption measurements.
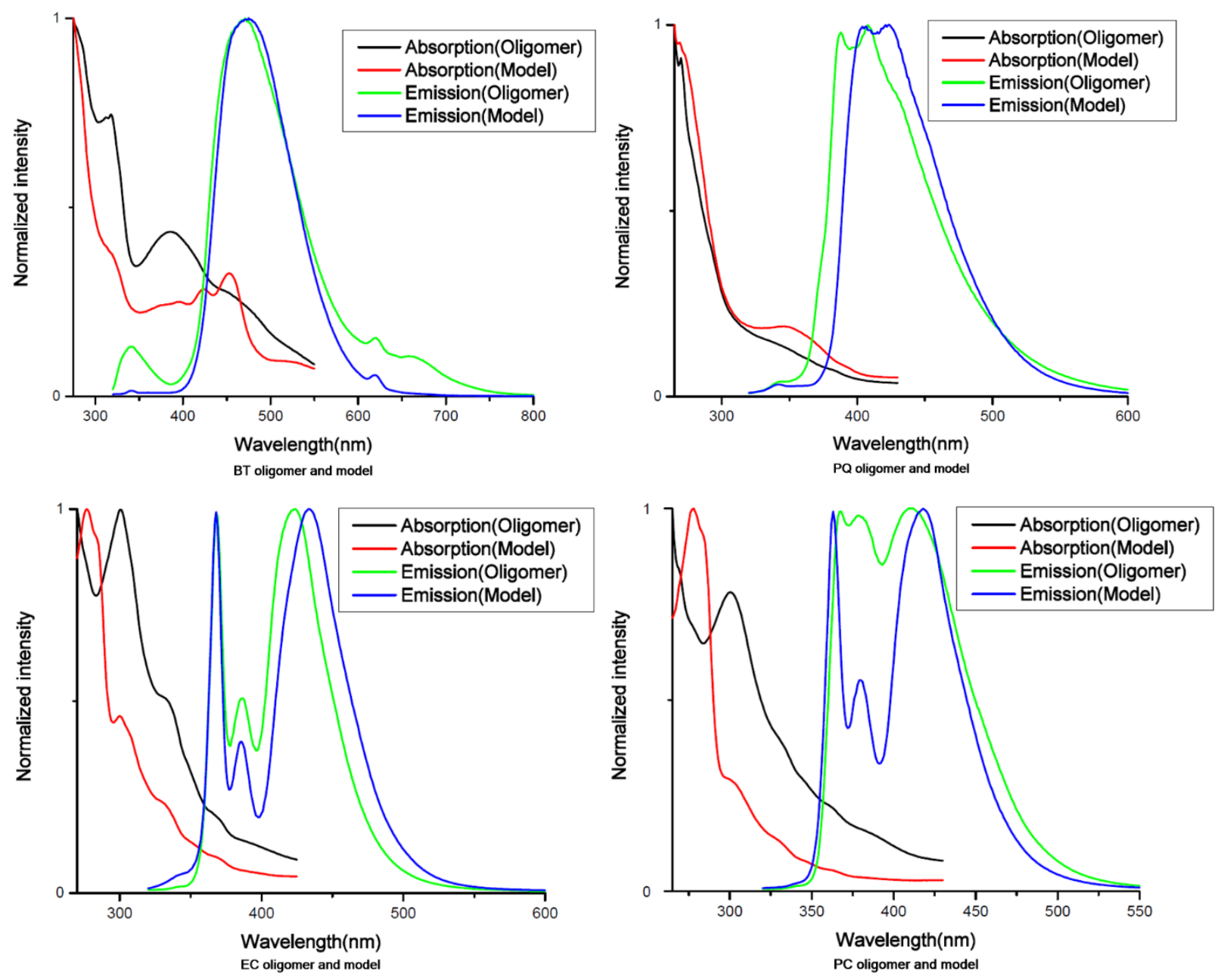

Figure 6. Emission-absorption profile for Benzothiadiazole, Phenanthrenequinone, Ethyl-carbazole, and Phenyl-carbazole oligomer and monomer (model compound) respectively.

Table 3. Steady state photophysical properties of BoC oligomers and model compounds. 


\begin{tabular}{|c|c|c|c|c|c|c|}
\hline Cross-linker & $\begin{array}{c}\lambda_{\max } \\
\text { (oligomer), } \\
\mathbf{n m}\end{array}$ & $\begin{array}{c}\text { Molar } \\
\text { absorptivity } \\
\text { (oligomer), } \varepsilon \\
\mathbf{1 0}^{4} \mathbf{M}^{-1} \mathbf{c m}^{-1}\end{array}$ & $\begin{array}{c}\lambda_{\text {max }} \text { (model } \\
\text { compound), } \\
\mathbf{n m}\end{array}$ & $\begin{array}{c}\text { Molar } \\
\text { absorptivity } \\
\text { (model } \\
\text { compound), } \varepsilon \\
\mathbf{1 0}^{4} \mathbf{M}^{-1} \mathbf{c m}^{-1}\end{array}$ & $\begin{array}{c}\text { PLQY } \\
\text { (oligomer) }\end{array}$ & $\begin{array}{c}\text { PLQY } \\
\text { (model } \\
\text { compound) }\end{array}$ \\
\hline \multirow{3}{*}{ Benzothiadiazole (BT) } & 270 & 2.00 & \multirow{3}{*}{$\begin{array}{l}423 \\
453\end{array}$} & \multirow{3}{*}{$\begin{array}{l}0.05 \\
0.21\end{array}$} & \multirow{3}{*}{0.09} & \multirow{3}{*}{0.59} \\
\hline & 320 & 1.05 & & & & \\
\hline & 385 & 0.48 & & & & \\
\hline \multirow[b]{2}{*}{ Phenanthrenequinone (PQ) } & 270 & 2.02 & \multirow[b]{2}{*}{350} & \multirow[b]{2}{*}{0.26} & \multirow[b]{2}{*}{0.62} & \multirow[b]{2}{*}{0.27} \\
\hline & 335 & 0.28 & & & & \\
\hline \multirow{2}{*}{ Ethyl-carbazole (EC) } & 300 & 3.01 & 278 & 0.44 & \multirow{2}{*}{0.04} & \multirow{2}{*}{0.43} \\
\hline & 333 & 1.15 & 301 & 0.17 & & \\
\hline \multirow{2}{*}{ Phenyl-carbazole (PC) } & 268 & 2.80 & 278 & 2.40 & \multirow{2}{*}{0.06} & \multirow{2}{*}{0.38} \\
\hline & 300 & 1.14 & 300 & 0.20 & & \\
\hline
\end{tabular}

Table 3 shows the steady-state optical properties of investigated oligomers and model compounds. Benzothiadiazole (BT) is an electron accepting moiety that is quite extensively used in light emitting devices. Typically, BT compounds show two distinct absorption maxima ranging from $270-500 \mathrm{~nm}$ due to $\pi-\pi^{*}$ transition. It has been reported that the low energy absorption bands occur due to intramolecular charge transfer states. ${ }^{76,77}$ BT-oligomer shows two distinct absorption maxima at 320 and $385 \mathrm{~nm}\left(\pi-\pi^{*}\right.$ transition), whereas the model has $\lambda_{\max }$ at 423 and $453 \mathrm{~nm}\left(\mathrm{n}-\pi^{*}\right.$ transition), suggesting there is an interaction between the linking BT and cage with a change in ground state absorption. In emission, the maxima are within $4 \mathrm{~nm}$ of each other, indicating no change in the emissive state but the PL QY decreased drastically indicating a partial ground state complex formation leading to a dark state. The $320 \mathrm{~nm}$ absorption maxima may arise from the phenyl groups on the SQs, which is notably absent in model BT. Typically, BT compounds have a very high luminescence. PLQY is quite high in model BT compared to the oligomer and is an indication of possible energy/charge migration through the oligomer or quenching by proximal phenyl cages (see transient absorption). The overlap of absorption and emission spectra indicates the possibility of self-absorption of the emission. The charge transfer transition $(453 \mathrm{~nm})$ is more prominent in the model BT than the oligomer. This might be the outcome of having $\pi-\pi^{*}$ states arising from the phenyls in the SQ cages which are absent in BT-model.

Phenanthrenequinone (PQ) shows both $n-\pi^{*}(350 \mathrm{~nm})$ and $\pi-\pi^{*}(270 \mathrm{~nm})$ transitions, the latter is the higher energy transition. Absorption spectra of PQ derivatives show two different bands with molar absorptivity in the range of $\sim 10^{3} .{ }^{78}$ The singlet-triplet gap is very close in PQ which makes the photophysical properties very interesting. It has been found that the ISC quantum yield for PQ is close to 1 where emitting state is triplet $n-\pi^{*} .{ }^{79-81}$ However, we saw an increased PL quantum yield in PQ oligomer compared to PQ-model. Typically, when the lowest excited state of aromatic ketones has $n-\pi^{*}$ character, intersystem crossing is known to have higher efficiency resulting in very low PLQY. This suggests that in oligomeric form, PQ might have predominant $\pi-\pi^{*}$ states (maybe a mixing) arising mostly from phenyls of the SQ cage, which decrease the intersystem crossing rate in PQ. This suggests that our increased PL QY results from global energy transfer within the combined phenyl SQ and PQ system to the central acceptor linker as a sink which can 
then release energy through fluorescence. We have found that shorter oligomers tend to be brighter as well. ${ }^{82}$

However, in PQ-model, the lowest energy excited state is less likely to be $\pi$ - $\pi^{*}$ and rather stems from a mixing of states with dominating $n-\pi^{*}$ character $(450 \mathrm{~nm})$. As a result, intersystem crossing rate is higher in the model compound responsible for lower PLQY than the oligomeric form. This property can be backed by the transient kinetic decay data (Figure S9) of model and oligomer PQ where model shows a slower kinetic decay than the PQ oligomer, meaning that model PQ has a longer lifetime in the excited state than the oligomer. Absorption and fluorescence spectra of PQmodel shows $\sim 16 \mathrm{~nm}$ red shift in emission compared to the oligomer. Time-resolved measurements were further able to explain why model PQ has lower luminescence quantum yield than the oligomer.

Carbazole is an electron donating group which is used in OLED and PLED systems as blue emitters. It is also a building block in donor-acceptor systems. Poly 9-vinylcarbazole is one of the compounds used in triplet emitters due to its high triplet energy. ${ }^{83}$ Here we have explored two different forms of carbazole (Table 3); N-ethyl-carbazole (EC) and 9-phenyl-carbazole (PC). In both the EC and PC systems, we observed enhanced absorption in the oligomers, especially at the lower energy $300 \mathrm{~nm}$ bands present as shoulders in the model compounds. It has been reported that high energy absorption bands arise from the $\pi-\pi^{*}$ transitions where low energy bands are due to the delocalization of electrons in the structure. ${ }^{83-85}$ In general, higher extinction coefficients have been observed in oligomers than the model compounds at specific $\lambda_{\text {max }}$ which shows higher photon absorption abilities in oligomer materials than their corresponding model structures, however accounting for repeat units they are similar. Higher absorption and lower PLQY (0.04 vs. $0.43 \mathrm{EC}$ oligomer and model respectively) in oligomers make them ideal structures towards any potential energy migration process. As the EC and PC are strong donor moieties, the oligomer systems allow for energy dissipation between groups that is not possible in the model, leading to lower emission quantum yields. Steady-state measurements have shown interesting ground and excited state interactions in oligomeric compounds. Time-resolved fluorescence as well as transient absorption measurements were carried out to understand the interactions between linker chromophores and silsesquioxane cage.

\section{Time Resolved Fluorescence Measurements}

Time-resolved fluorescence measurements were carried out using time-correlated single photon counting technique after excitation with $370 \mathrm{~nm}$ diode and monitoring the fluorescence at their corresponding fluorescence maxima. Table S1 shows the average fluorescence lifetimes of monomers and oligomers obtained from the fluorescence decays. As can be seen from Table S1, the fluorescence lifetimes of oligomeric compounds are lower than the model counterparts suggesting excited-state interactions. The decrease in lifetime can either be ascribed to energy transfer between the chromophores or charge-transfer interactions between the linker chromophore and cage or vice-versa. As the time-resolution of the time-resolved instrument is longer (FWHM $\sim 1.1 \mathrm{~ns}$ ), they were unable to monitor early time deactivation pathways that might be prominent in oligomeric compounds. Thus, ultrafast transient absorption measurements were carried out to further probe the excited-state interactions.

\section{Time-resolved transient absorption measurements}


Optical absorption, steady-state and time-resolved fluorescence measurements have shown that there are both excited state and ground state interactions between the linker chromophores and aromatic groups around the cage. To understand the interactions at ultrafast time scales, transient absorption measurements were carried out on both model and oligomeric compounds, exciting the linker chromophores at $370 \mathrm{~nm}$.

Transient absorption measurements were carried out on model and oligomeric Benzothiadiazole (BT) compounds after excitation at $370 \mathrm{~nm}$. Figure 7A shows the ESA at different time delays for BT-model compound. The ESA at different time delays show broad positive absorption with a maximum at $650 \mathrm{~nm}$ with no other distinctive features and all the transients decayed with increase in time delay. Note the signal is rather small for BT-model as the absorption at the excitation wavelength is low. Figure 7B shows the species-associated spectra obtained from global fit analysis that resulted in two decay components: $6.5 \mathrm{ps}$ and $>1 \mathrm{~ns}$. Both components have the same spectrum suggesting that they are arise out of the same state. The longer decay is ascribed to the decay of the singlet excited state. Similarly, the ESA of BT-oligomer at different time delays were presented in Figure 7C (early time delays 200 fs to 4.5 ps) and Figure 7D (4.5 ps to $950 \mathrm{ps}$ ). Note that the transient spectral features of BT-oligomer are distinctly different from BT-model suggesting electronic interaction between the linker chromophores and the cage. Note that the signal for BT-oligomer is rather higher when compared to model compound as the absorbance at $370 \mathrm{~nm}$ is higher for the oligomer. (Figure 6A) At initial time delays, the ESA peak with a maximum around $640 \mathrm{~nm}$ was observed along with a shoulder at $550 \mathrm{~nm}$. With increase in time delay from 200 fs to $4.5 \mathrm{ps}$, the shoulder at $550 \mathrm{~nm}$ decayed slightly and spectral growth is observed at $640 \mathrm{~nm}$. After that all transients decayed with increase in time delay (Figure 7D). Species-associated spectrum for BT-oligomer was obtained from global fit analysis and is shown in Figure 7E. As expected, one can observe a growth component of 520 fs followed by a long-lived state. The data suggests the presence of two different excited states in the decay of BToligomer, distinctly different from BT-model. Transient absorption data shows that there are no ultrafast excited state interactions in BT-oligomer and the lower fluorescence lifetime observed for BT-oligomer, probably is arising from different excited states for the oligomer over the model compound. 

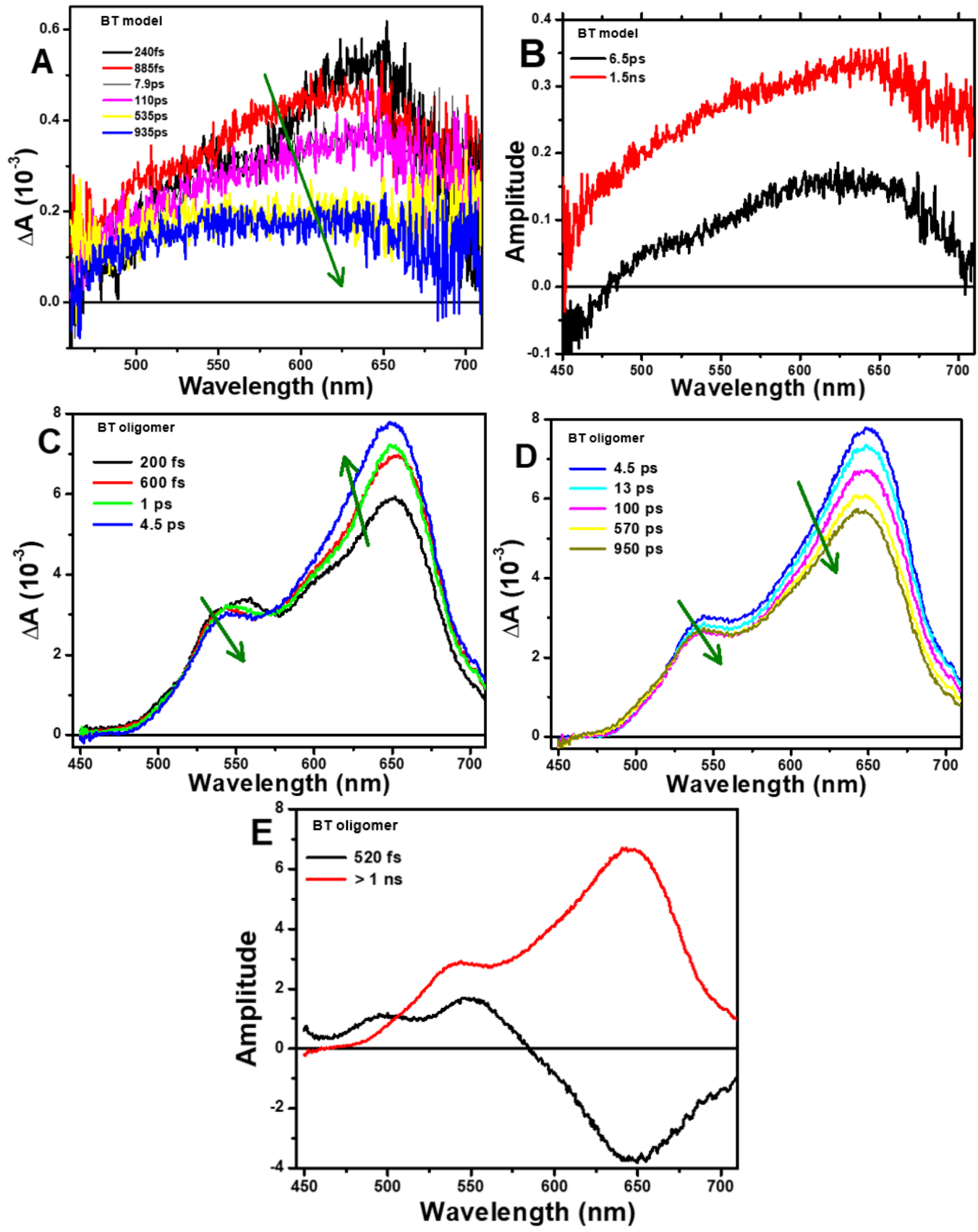

Figure 7. (A-D) Excited state absorption at different time delays for BT-model and BT-oligomer and (E) Corresponding species-associated spectrum.

Transient absorption measurements were also carried out for model and oligomeric PQ compounds and the data is presented in Figure 8. Figure 8A shows the ESA at different time delays for model PQ. Broad ESA with a maximum around $670 \mathrm{~nm}$ was observed which decayed with an increase in time delay. Species-associated spectrum obtained from global fit analysis (Figure $8 \mathrm{~B}$ ) yielded one major component, that is dominated by the decay of the fluorescent state of model PQ. Optical absorption measurements have shown slightly different absorption spectra for PQoligomer when compared to PQ-model suggesting ground state interactions between PQ and phenyl rings of the cage. Also, the fluorescence maximum of PQ-oligomer has shifted to higher 
energies when compared to PQ-model, indicating excited state interactions. Interesting transient absorption spectral features were observed for PQ-oligomer. Shown in Figure 8C are the ESA at different time delays for PQ-oligomer. The data shows ESA with a maximum at $640 \mathrm{~nm}$ that decayed with increase in time delay. Faster decay was observed for PQ-oligomer which is not as evident in PQ-model. Species-associated spectra of PQ-oligomer (Figure 8D) has yielded two components: 2.2 ps and $>1 \mathrm{~ns}$. The faster component can be ascribed to partial charge-transfer interaction between the linking chromophore and the phenyl rings of cage, correlating to the decrease in PLQY (Table 3). However, energy transfer between the chromophores cannot be completely ruled out.
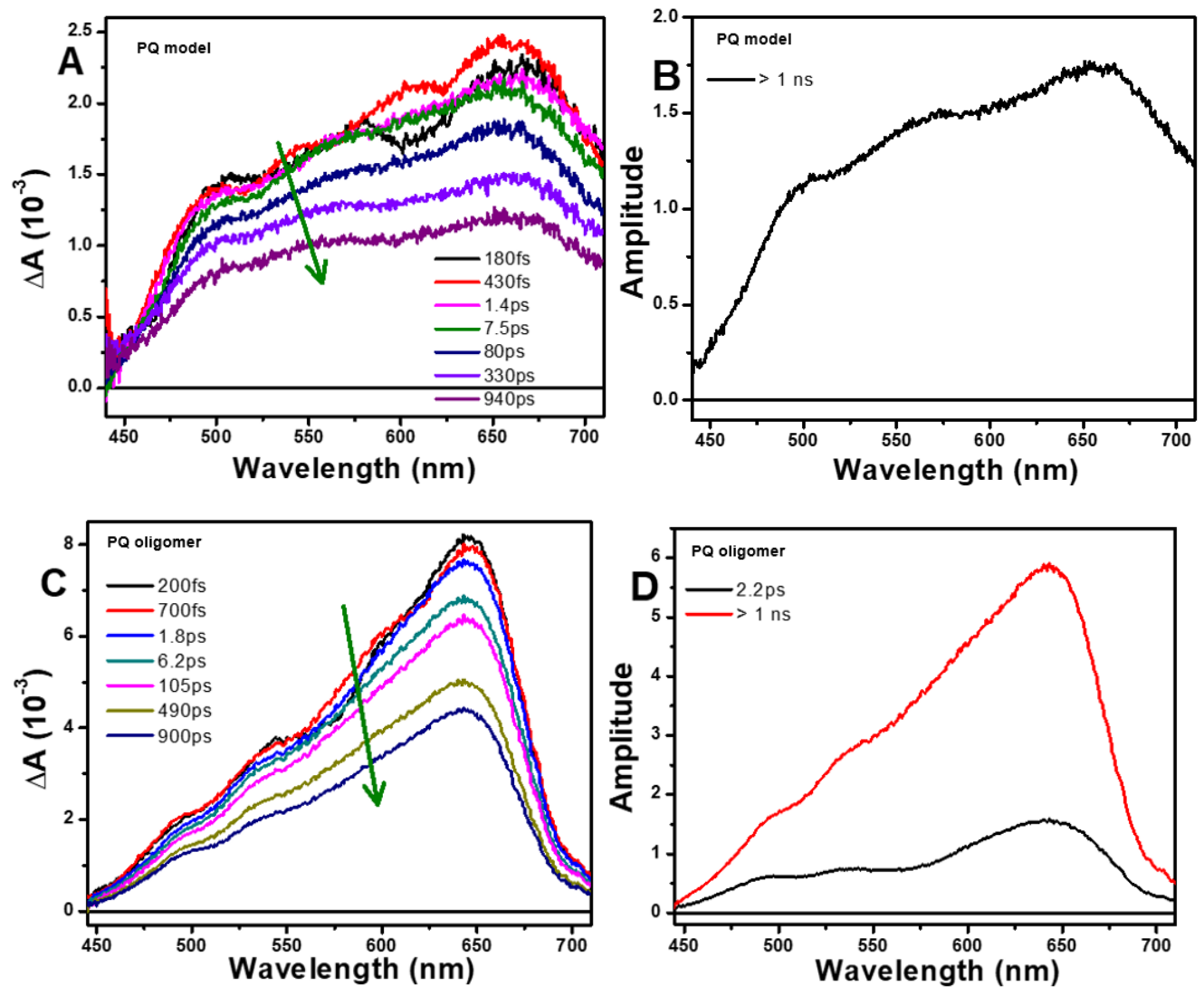

Figure 8. Excited state absorption spectra at different time delays for (A) PQ-model and (C) PQ-Oligomer. Species-associated spectra obtained from global fit analysis for (B) PQ-model and (D) PQ-Oligomer.

Transient absorption measurements were also carried out for carbazole based model and oligomeric compounds. Transient spectral features of model and oligomeric PC are presented in Figure 9. Figure 9A shows the ESA at different time delays for monomeric PC. The spectra show broad featureless positive absorption band with a maximum centered at $640 \mathrm{~nm}$ which decayed with increase in time delay. Species associated spectra of model PC has shown two main decay components: 260 ps and $>1$ ns (fluorescent state). The transient absorption spectra at different delays for oligomeric PC are shown in Figure 9C. The spectra for oligomer-PC has shown a broad ESA with maximum around $640 \mathrm{~nm}$, which decayed with increase in time delay. However, the species-associated spectra of oligomeric PC (Figure 9D) has yielded three different components: $5.8 \mathrm{ps}, 80 \mathrm{ps}$ and $>1 \mathrm{~ns}$. The long lifetime determined from the decay matched well with the fluorescence lifetime of the oligomeric PC. Optical absorption spectra of oligomer PC (Figure 6C) 
is shifted to longer wavelengths when compared with the model PC indicating there is ground state interactions. Note the ESA features of oligomer PC are different from the model PC suggesting that there is a difference in the nature of excited states as well. The presence of faster decay component in the oligomer PC suggests either charge or energy transfer interaction that resulted in faster deactivation. Note the absence of any new transients in the ESA of oligomer PC prove the absence of charge-transfer interactions and the faster decay component can be ascribed to energy transfer between the linker chromophores in oligomer PC. Additional transient absorption anisotropy measurements were carried out to probe the same (discussed below). Similar transient absorption spectral features were observed for model and oligomeric EC compounds.
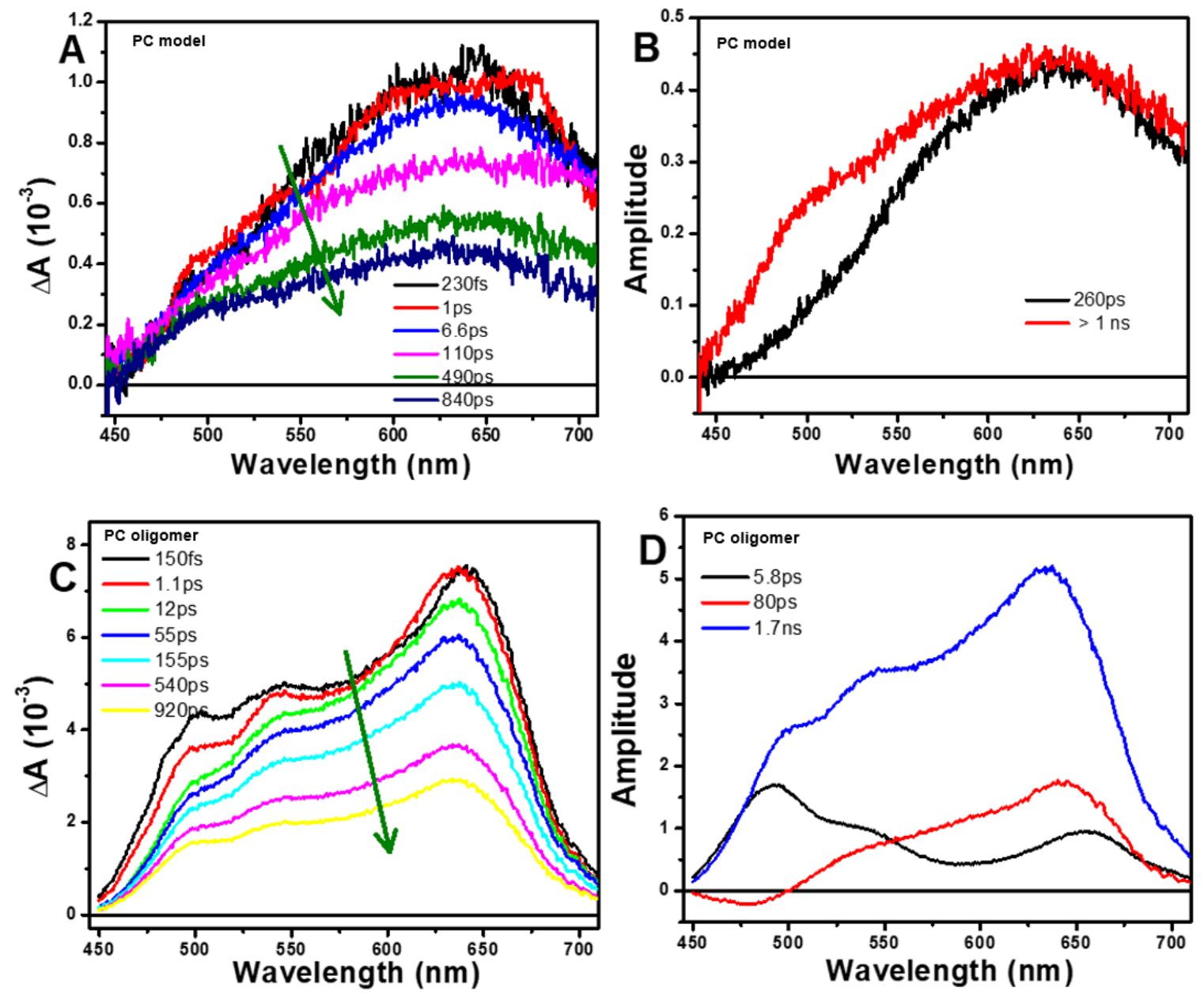

Figure 9. Excited state absorption spectra at different time delays for Phenyl carbazole (PC) (A) model, (C) PC Oligomer. Species associated spectra obtained from global fit analysis for (B) PCmodel and (D) PC-oligomer.

Distinctly different excited state relaxation is observed for oligomeric compounds that can be assigned to either charge transfer, energy transfer between the chromophores or chromophore to core or vice-versa. However, transient absorption spectral features alone were not sufficient to differentiate the charge-transfer or energy transfer deactivation in oligomeric compounds. Thus, we have used femtosecond transient absorption anisotropy measurements to differentiate energy 
transfer and charge-transfer interactions. Transient absorption anisotropy measurements were able to probe intrinsic energy transfer in molecular systems, light harvesting antennae, among others. ${ }^{86-}$ 89 Anisotropy measurements are mostly aimed at molecules as the dipoles are aligned in one direction and if the dipole is parallel to excitation, one can expect an anisotropy of $0.4 .{ }^{90}$ If there is an energy transfer from chromophore to chromophore, one can expect a change in anisotropy decay. Oligomeric compounds usually show longer anisotropy decays when compared to monomers as their molar volume is higher. If there is ultrafast energy transfer in oligomeric compounds, one can expect faster anisotropy decay in oligomeric compound.

Figure 10A shows the anisotropy decay comparison of the model and oligomeric PQ. Oligomeric PQ does show longer anisotropy decay when compared to model PQ without any faster anisotropy decay, indicating the absence of any energy transfer deactivation in PQ. Faster lifetime decay observed in oligomeric PQ can be ascribed to charge transfer interactions between the linker chromophore and the phenyl rings of the silsesquioxane cage rather than energy transfer. The anisotropy data for BT-model is rather noisy as the signal is lower. However, BT-oligomer has shown (Figure 10B) anisotropy decay component of 85 ps along with longer anisotropy decay. This 85 ps decay component for BT-oligomer can be assigned to energy transfer between the linking chromophores. Similarly, carbazole based compounds show interesting anisotropy decays (Figure 10C and 10D). Note from Figures that the model EC and PC show mono-exponential decay that can be ascribed to rotational relaxation of model compounds. In contrast, interesting anisotropy decay is observed for oligomeric EC and PC. Firstly, the initial anisotropy of oligomeric $\mathrm{EC}$ and PC is smaller than their monomeric counterparts that can be ascribed to excitation delocalization between the linking chromophore and cage. Secondly, two exponential anisotropy decay is observed for oligomeric EC and PC, one is in 10's of ps and other around $800 \mathrm{ps.} \mathrm{Longer}$ anisotropy decay is again rotational relaxation of oligomeric compounds. The 10's of ps anisotropy decay can be attributed to energy transfer between the linking chromophores in oligomeric EC and PC. The anisotropy decay components are presented in Table S2. Overall, energy transfer between chromophores was observed in BT, EC, and PC systems while no such energy transfer was observed in PQ. This can be assigned to the spectral overlap differences determined for these systems as discussed as HOMO-FRET in the steady-state spectroscopy.
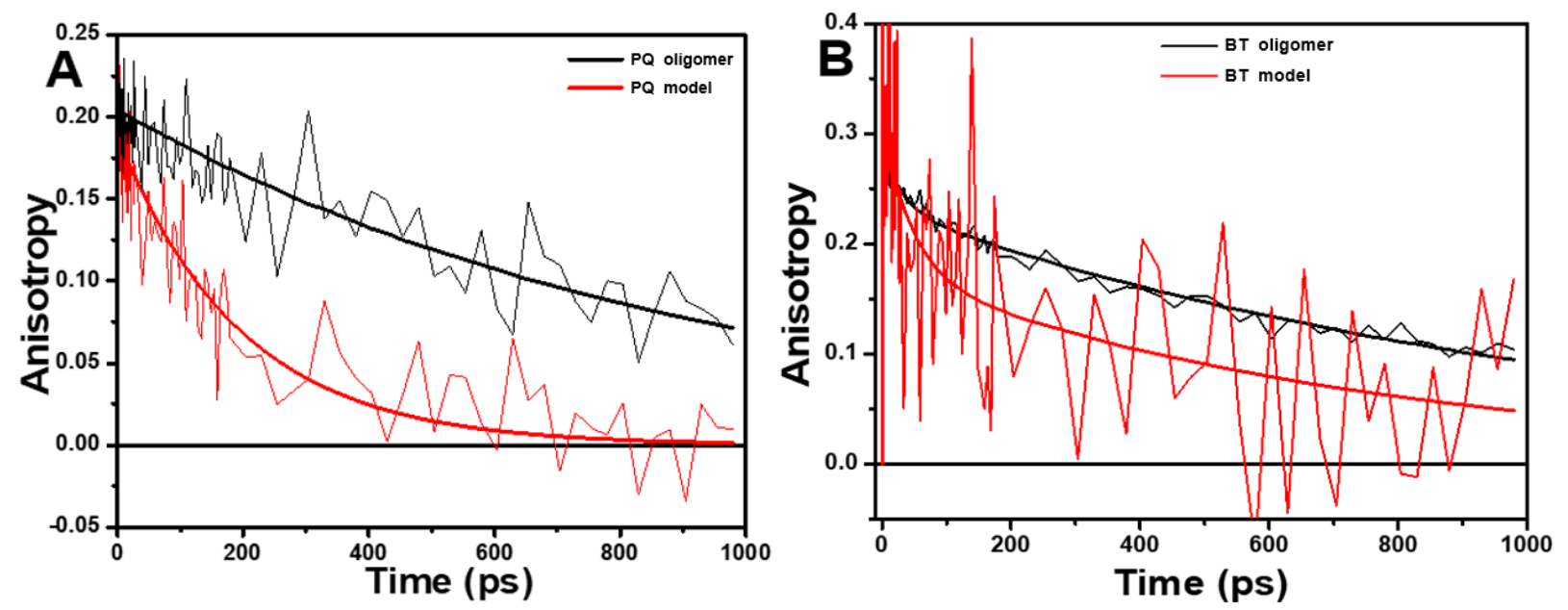

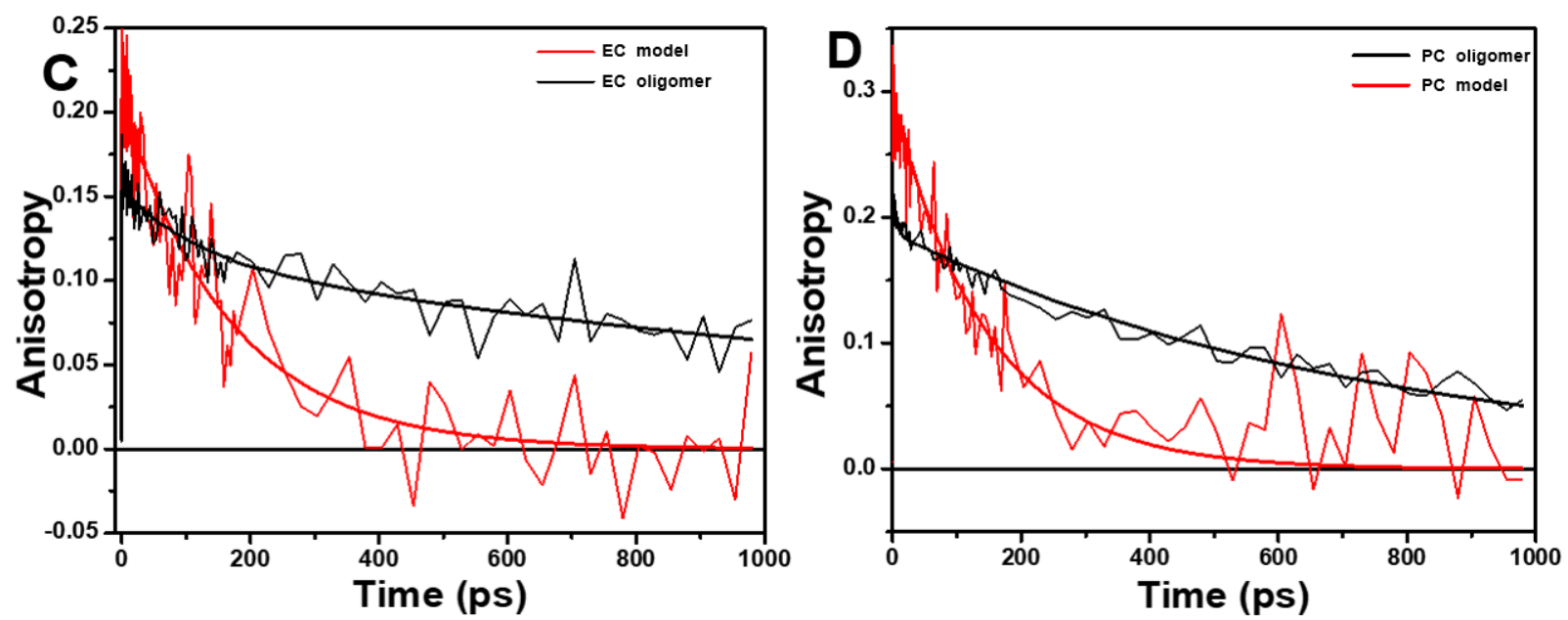

Figure 10: Comparison of anisotropy decays for (A) Benzothiadiazole (BT), (B) Phenanthrenequinone (PQ), (C) Ethyl-carbazole (EC), and (D) Phenyl-carbazole (PC) oligomer and model compound, respectively.

\section{Conclusions}

The photophysical properties of beads on a chain $(\mathrm{BoC})$ oligomers depend on the uniformity in structures as well as their orientations in both ground and excited states. Close proximities between linkers and cages are facilitated due to large sizes of SQs. Thus, they behave like homoFRET systems; excitation energy being transferred intra-chain which was confirmed by ultrafast measurements. Our systems provide better flexibility in terms of attaching different cross-linkers with a wide range of absorptions in UV/visible region with increased molar absorptivity by simple cross-coupling methods. Ultrafast energy hopping process' through oligomers has been explored by transient absorption anisotropy experiment that justifies the proposed SQ cage-linker spectroscopic relationship. Initial photophysical analyses have showed evidence of excitation energy migration through the oligomeric systems, lowering fluorescence quantum yields compared to the respective model compounds. Transient absorption anisotropy measurements have shown energy transfer between chromophores in the case of BT, EC, and PC compounds while no such energy transfer was seen in PQ. However, interaction between the linker and phenyl rings of the cage was evident in the case of PQ. We believe these interactions are dictated by the chain lengths or number of repeating units present in the structure. Due to the structural flexibility, the communication between linkers and cages are possible even at very low concentrations.

\section{Acknowledgements}

JCF and SM thank Bowling Green State University for Startup Funding.. We thank Dr. Gary Wiederrecht for his help with transient absorption measurements. Use of the Center for Nanoscale Materials, an Office of Science user facility, was supported by the U.S. Department of Energy, Office of science, office of Basic Energy Sciences, under Contract No. DE-AC02-06CH11357

\section{Author Information}

Corresponding Author 
Joseph C. Furgal - Department of Chemistry and Center for Photochemical Sciences, Bowling Green State University, Bowling Green, Ohio 43403 USA

https://orcid.org/0000-0002-7040-0793 Email: furgalj@,bgsu.edu

\section{$\underline{\text { Authors }}$}

Shahrea Mahbub - Department of Chemistry and Center for Photochemical Sciences, Bowling Green State University, Bowling Green, Ohio 43403 USA. Email: smahbub@bgsu.edu

Sukanya Saha - Department of Chemistry and Biochemistry, Western Michigan University, Kalamazoo, MI 49008 USA. Email: sukanya.saha@wmich.edu

Guda Ramakrishna- Department of Chemistry and Biochemistry, Western Michigan University, Kalamazoo, MI 49008 USA. Email: rama.guda@wmich.edu

\section{Conflict of Interest}

The authors declare no competing conflicts of interest for this work.

\section{Electronic Supporting Information}

Detailed spectroscopic characterization including NMR, FTIR, TGA, MALDI-ToF and Time Dependent Fluorescence data are included in the electronic supporting information and is available free of charge from https://pubs.acs.org

\section{References:}

(1) Ahmad, J.; Bazaka, K.; Anderson, L. J.; White, R. D.; Jacob, M. V. Materials and Methods for Encapsulation of OPV: A Review. Renew. Sustain. Energy Rev. 2013, 27, 104-117. https://doi.org/10.1016/j.rser.2013.06.027.

(2) Carlé, J. E.; Krebs, F. C. Technological Status of Organic Photovoltaics (OPV). Sol. Energy Mater. Sol. Cells 2013, 119, 309-310. https://doi.org/10.1016/j.solmat.2013.08.044.

(3) Horowitz, G.; Deloffre, F.; Garnier, F.; Hajlaoui, R.; Hmyene, M.; Yassar, A. All-Organic Field-Effect Transistors Made of $\pi$-Conjugated Oligomers and Polymeric Insulators. Synth. Met. 1993, 54 (1-3), 435-445. https://doi.org/10.1016/0379-6779(93)91089-K.

(4) Hains, A. W.; Liang, Z.; Woodhouse, M. A.; Gregg, B. A. Molecular Semiconductors in Organic Photovoltaic Cells. Chem. Rev. 2010, 110 (11), 6689-6735. https://doi.org/10.1021/cr9002984.

(5) Huang, T.; Jiang, W.; Duan, L. Recent Progress in Solution Processable TADF Materials for Organic Light-Emitting Diodes. J. Mater. Chem. C 2018, 6 (21), 5577-5596. https://doi.org/10.1039/c8tc01139g.

(6) Lo, M. Y.; Zhen, C.; Lauters, M.; Jabbour, G. E.; Sellinger, A. Organic-Inorganic Hybrids 
Based on Pyrene Functionalized Octavinylsilsesquioxane Cores for Application in OLEDs. J. Am. Chem. Soc. 2007, 129, 5808-5809.

(7) O'Neill, M.; Kelly, S. M. Ordered Materials for Organic Electronics and Photonics. Adv. Mater. 2011, 23 (5), 566-584. https://doi.org/10.1002/adma.201002884.

(8) Sekine, C.; Tsubata, Y.; Yamada, T.; Kitano, M.; Doi, S. Recent Progress of High Performance Polymer OLED and OPV Materials for Organic Printed Electronics. Sci. Technol. Adv. Mater. 2014, 15 (3). https://doi.org/10.1088/1468-6996/15/3/034203.

(9) Duan, L.; Hou, L.; Lee, T. W.; Qiao, J.; Zhang, D.; Dong, G.; Wang, L.; Qiu, Y. Solution Processable Small Molecules for Organic Light-Emitting Diodes. J. Mater. Chem. 2010, 20 (31), 6392-6407. https://doi.org/10.1039/b926348a.

(10) Nuyken, O.; Bacher, E.; Braig, T.; Fáber, R.; Mielke, F.; Rojahn, M.; Wiederhirn, V.; Meerholz, K.; Müller, D. Crosslinkable Hole- and Electron-Transport Materials for Application in Organic Light Emitting Devices (OLEDs). Des. Monomers Polym. 2002, 5 (2-3), 195-210. https://doi.org/10.1163/156855502760157926.

(11) Chan, K. L.; Sonar, P.; Sellinger, A. Cubic Silsesquioxanes for Use in Solution Processable Organic Light Emitting Diodes (OLED). J. Mater. Chem. 2009, 19 (48), 9103. https://doi.org/10.1039/b909234j.

(12) Zhong, C.; Duan, C.; Huang, F.; Wu, H.; Cao, Y. Materials and Devices toward Fully Solution Processable Organic Light-Emitting Diodes. Chem. Mater. 2011, 23 (3), 326340. https://doi.org/10.1021/cm101937p.

(13) Fyfe, D. LED Technology: Organic Displays Come of Age. Nat. Photonics 2009, 3 (8), 453-455. https://doi.org/10.1038/nphoton.2009.132.

(14) Nikolaenko, A. E.; Cass, M.; Bourcet, F.; Mohamad, D.; Roberts, M. Thermally Activated Delayed Fluorescence in Polymers: A New Route toward Highly Efficient Solution Processable OLEDs. Adv. Mater. 2015, 27 (44), 7236-7240. https://doi.org/10.1002/adma.201501090.

(15) Nuyken, O.; Jungermann, S.; Wiederhirn, V.; Bacher, E.; Meerholz, K. Modern Trends in Organic Light-Emitting Devices (OLEDs). Monatshefte fur Chemie 2006, 137 (7), 811824. https://doi.org/10.1007/s00706-006-0490-4.

(16) Geffroy, B.; le Roy, P.; Prat, C. Organic Light-Emitting Diode (OLED) Technology: Materials, Devices and Display Technologies. Polym. Int. 2006, 55 (6), 572-582. https://doi.org/10.1002/pi.1974.

(17) Liu, Y.; Li, C.; Ren, Z.; Yan, S.; Bryce, M. R. All-Organic Thermally Activated Delayed Fluorescence Materials for Organic Light-Emitting Diodes. Nat. Rev. Mater. 2018, 3. https://doi.org/10.1038/natrevmats.2018.20.

(18) Kulkarni, A. P.; Tonzola, C. J.; Babel, A.; Jenekhe, S. A. Electron Transport Materials for Organic Light-Emitting Diodes. Chem. Mater. 2004, 16 (23), 4556-4573. https://doi.org/10.1021/cm0494731.

(19) Yook, K. S.; Lee, J. Y. Small Molecule Host Materials for Solution Processed 
Phosphorescent Organic Light-Emitting Diodes. Adv. Mater. 2014, 26 (25), 4218-4233. https://doi.org/10.1002/adma.201306266.

(20) Muccini, M. A Bright Future for Organic Field-Effect Transistors. Nat. Mater. 2006, 5 (8), 605-613. https://doi.org/10.1038/nmat1699.

(21) Nunzi, J. M. Organic Photovoltaic Materials and Devices. Comptes Rendus Phys. 2002, 3 (4), 523-542. https://doi.org/10.1016/S1631-0705(02)01335-X.

(22) Forrest, S. R. The Path to Ubiquitous and Low-Cost Organic Electronic Appliances on Plastic. Nature 2004, 428 (6986), 911-918. https://doi.org/10.1038/nature02498.

(23) Guo, X.; Baumgarten, M.; Müllen, K. Designing $\pi$-Conjugated Polymers for Organic Electronics. Prog. Polym. Sci. 2013, 38 (12), 1832-1908.

https://doi.org/10.1016/j.progpolymsci.2013.09.005.

(24) Zhou, H.; Ye, Q.; Xu, J. Polyhedral Oligomeric Silsesquioxane-Based Hybrid Materials and Their Applications. Mater. Chem. Front. 2017, 1 (2), 212-230.

https://doi.org/10.1039/c6qm00062b.

(25) Du, Y.; Liu, H. Cage-like Silsesquioxanes-Based Hybrid Materials. Dalt. Trans. 2020, 49 (17), 5396-5405. https://doi.org/10.1039/d0dt00587h.

(26) Ye, Q.; Zhou, H.; Xu, J. Cubic Polyhedral Oligomeric Silsesquioxane Based Functional Materials: Synthesis, Assembly, and Applications. Chem. - An Asian J. 2016, 11 (9), 1322-1337. https://doi.org/10.1002/asia.201501445.

(27) Yang, X.; Liu, H. Diphenylphosphine-Substituted Ferrocene/Silsesquioxane-Based Hybrid Porous Polymers as Highly Efficient Adsorbents for Water Treatment. ACS Appl. Mater. Interfaces 2019, 11 (29), 26474-26482. https://doi.org/10.1021/acsami.9b07874.

(28) Cheng, X. e.; Liu, S.; Shi, W. Synthesis and Properties of Silsesquioxane-Based Hybrid Urethane Acrylate Applied to UV-Curable Flame-Retardant Coatings. Prog. Org. Coatings 2009, 65 (1), 1-9. https://doi.org/10.1016/j.porgcoat.2008.08.018.

(29) Arsalani, N.; Kazeminava, F.; Akbari, A.; Hamishehkar, H.; Jabbari, E.; Kafil, H. S. Synthesis of Polyhedral Oligomeric Silsesquioxane Nano-Crosslinked Poly(Ethylene Glycol)-Based Hybrid Hydrogels for Drug Delivery and Antibacterial Activity. Polym. Int. 2019, 68 (4), 667-674. https://doi.org/10.1002/pi.5748.

(30) Tanaka, K.; Chujo, Y. Advanced Functional Materials Based on Polyhedral Oligomeric Silsesquioxane (POSS). J. Mater. Chem. 2012, 22 (5), 1733-1746. https://doi.org/10.1039/c1jm14231c.

(31) Fu, Z.; Xu, K.; Liu, X.; Wu, J.; Tan, C.; Chen, M. Preparation and Properties of Hybrid Materials Originating from Polybenzoxazines and Silsesquioxanes. Macromol. Chem. Phys. 2013, 214 (10), 1122-1130. https://doi.org/10.1002/macp.201200604.

(32) Li, W.; Jiang, C.; Liu, H.; Yan, Y.; Liu, H. Octa[4-(9-Carbazolyl)Phenyl]SilsesquioxaneBased Porous Material for Dyes Adsorption and Sensing of Nitroaromatic Compounds. Chem. - An Asian J. 2019, 14 (19), 3363-3369. https://doi.org/10.1002/asia.201900951. 
(33) Gnanasekaran, D.; Madhavpan, K.; Reddy, R. S. R. Developments of Polyhedral Oligomeric Silsesquioxanes (POSS), POSS Nanocomposites and Their Applications: A Review. J. Sci. Ind. Res. (India). 2009, 68 (6), 437-464.

(34) Li, G.; Wang, L.; Ni, H.; Pittman, C. U. Polyhedral Oligomeric Silsesquioxane (POSS) Polymers and Copolymers: A Review. J. Inorg. Organomet. Polym. 2001, 11 (3), 123154. https://doi.org/10.1023/A:1015287910502.

(35) Ervithayasuporn, V.; Abe, J.; Wang, X.; Matsushima, T.; Murata, H.; Kawakami, Y. Synthesis, Characterization, and OLED Application of Oligo(p-Phenylene Ethynylene)s with Polyhedral Oligomeric Silsesquioxanes (POSS) as Pendant Groups. Tetrahedron 2010, 66 (48), 9348-9355. https://doi.org/10.1016/j.tet.2010.10.009.

(36) Froehlich, J. D.; Young, R.; Nakamura, T.; Ohmori, Y.; Li, S.; Mochizuki, A.; Lauters, M.; Jabbour, G. E. Synthesis of Multi-Functional POSS Emitters for OLED Applications. Chem. Mater. 2007, 19 (20), 4991-4997. https://doi.org/10.1021/cm070726v.

(37) Yang, X.; Froehlich, J. D.; Chae, H. S.; Harding, B. T.; Li, S.; Mochizuki, A.; Jabbour, G. E. Efficient Light-Emitting Devices Based on Platinum-Complexes-Anchored Polyhedral Oligomeric Silsesquioxane Materials. Chem. Mater. 2010, 22 (16), 4776-4782. https://doi.org/10.1021/cm101314b.

(38) Zhang, T.; Wang, J.; Zhou, M.; Ma, L.; Yin, G.; Chen, G.; Li, Q. Influence of Polyhedral Oligomeric Silsesquioxanes (POSS) on Blue Light-Emitting Materials for OLED.

Tetrahedron 2014, 70 (14), 2478-2486. https://doi.org/10.1016/j.tet.2013.11.082.

(39) Dudziec, B.; Zak, P.; Marciniec, B. Synthetic Routes to Silsesquioxane-Based Systems as Photoactive Materials and Their Precursors. Polymers (Basel). 2019, 11 (3).

https://doi.org/10.3390/polym11030504.

(40) Mironenko, A. Y.; Tutov, M. V.; Sergeev, A. A.; Voznesenskiy; Bratskaya, S. Y. On/off Rhodamine Based Fluorescent Probe for Detection of Au and Pd in Aqueous Solutions. Sensors Actuators, B Chem. 2017, 246, 389-394. https://doi.org/10.1016/j.snb.2017.02.092.

(41) Sellinger, A.; Tamaki, R.; Laine, R. M.; Ueno, K.; Tanabe, H.; Williams, E.; Jabbour, G. E. Heck Coupling of Haloaromatics with Octavinylsilsesquioxane: Solution Processable Nanocomposites for Application in Electroluminescent Devices. Chem. Commun. (Camb). 2005, No. 29, 3700-3702. https://doi.org/10.1039/b505048k.

(42) Jung, J. H.; Furgal, J.; III, T. G.; Mizumo, T.; Schwartz, M.; Chou, K.; Vonet, J.-F.; Laine, R. M. 3-D Molecular Mixtures of Catalytically Functionalized [VinylSiO1.5]10/ [VinylSiO1.5]12. Photophysical Characterization of Second Generation Derivatives. Chem. Mater. 2012, 24, 1883-1895.

(43) Sulaiman, S.; Zhang, J.; Goodson, I. T.; Laine, R. M. Synthesis, Characterization and Photophysical Properties of Polyfunctional Phenylsilsesquioxanes: [O-RPhSiO1.5]8, [2,5R2PhSiO1.5]8, and [R3PhSiO1.5]8. Compounds with the Highest Number of Functional Units/Unit Volume. J. Mater. Chem. 2011, 21 (30), 11177. https://doi.org/10.1039/c1jm11701g. 
(44) Miniewicz, A.; Girones, J.; Karpinski, P.; Mossety-Leszczak, B.; Galina, H.; Dutkiewicz, M. Photochromic and Nonlinear Optical Properties of Azo-Functionalized POSS Nanoparticles Dispersed in Nematic Liquid Crystals. J. Mater. Chem. C 2014, 2 (3), 432440. https://doi.org/10.1039/c3tc31791a.

(45) Liu, Y.; Yang, W.; Liu, H. Azobenzene-Functionalized Cage Silsesquioxanes as Inorganic-Organic Hybrid, Photoresponsive, Nanoscale, Building Blocks. Chem. - A Eur. J. 2015, 21 (12), 4731-4738. https://doi.org/10.1002/chem.201406142.

(46) Pérez-Ojeda, M. E.; Trastoy, B.; Lõpez-Arbeloa, Í.; Bañuelos, J.; Costela, Ú.; GarcíaMoreno, I.; Chiara, J. L. Click Assembly of Dye-Functionalized Octasilsesquioxanes for Highly Efficient and Photostable Photonic Systems. Chem. - A Eur. J. 2011, 17, 1325813268. https://doi.org/10.1002/chem.201100512.

(47) Clarke, D. J.; Matisons, J. G.; Simon, G. P.; Samoc, M.; Samoc, A. Polyhedral Oligomeric Silsesquioxane-Bound Iminofullerene. Appl. Organomet. Chem. 2010, 24 (April 2009), 184-188. https://doi.org/10.1002/aoc.1568.

(48) Furgal, J. C.; Jung, J. H.; Goodson III, T.; Laine, R. M. Analyzing StructurePhotophysical Property Relationships for Isolated T8, T10, and T12

Stilbenevinylsilsesquioxanes. J. Am. Chem. Soc. 2013, 135, 12259-12269. https://doi.org/10.1021/ja4043092.

(49) Phillips, H.; Zheng, S.; Hyla, A.; Laine, R.; Goodson, T.; Geva, E.; Dunietz, B. D. Ab Initio Calculation of the Electronic Absorption of Functionalized Octahedral Silsesquioxanes via Time-Dependent Density Functional Theory with Range-Separated Hybrid Functionals. J. Phys. Chem. A 2012, 116 (4), 1137-1145.

(50) Wang, D.; Li, L.; Yang, W.; Zuo, Y.; Feng, S.; Liu, H. POSS-Based Luminescent Porous Polymers for Carbon Dioxide Sorption and Nitroaromatic Explosives Detection. RSC Adv. 2014, 4 (104), 59877-59884. https://doi.org/10.1039/c4ra11069b.

(51) Hu, N.; Furgal, J. C. Photoreversible Loading and Unloading of Q-Silsesquioxane Dynamic Network Sponges. Adv. Funct. Mater. 2020, Accepted M. https://doi.org/10.1002/adfm.202010114.

(52) Xu, L.; Manda, V. R.; McNamara, L. E.; Jahan, M. P.; Rathnayake, H.; Hammer, N. I. Covalent Synthesis of Perylenediimide-Bridged Silsesquioxane Nanoribbons and Their Electronic Properties. RSC Adv. 2014, 4 (57), 30172-30179. https://doi.org/10.1039/c4ra03260h.

(53) Hu, N.; Furgal, J. C. Photoreversible Loading and Unloading of Q - Silsesquioxane Dynamic Network Sponges. Adv. Funct. Mater. 2021, 31 (2010114), 1-11. https://doi.org/10.1002/adfm.202010114.

(54) Asuncion, M. Z.; Laine, R. M. Fluoride Rearrangement Reactions of Polyphenyl- and Polyvinylsilsesquioxanes as a Facile Route to Mixed Functional Phenyl, Vinyl T 10 and T 12 Silsesquioxanes. J. Am. Chem. Soc. 2010, 132 (11), 3723-3736. https://doi.org/10.1021/ja9087743.

(55) Jung, J. H.; Furgal, J. C.; Clark, S.; Schwartz, M.; Chou, K.; Laine, R. M. Beads on a 
Chain (BoC) Polymers with Model Dendronized Beads. Copolymerization of [(4-NH $2 \mathrm{C}$ $6 \mathrm{H} 4 \mathrm{SiO} 1.5) 6(\mathrm{IPhSiO} 1.5$ ) 2 ] and [(4-CH $3 \mathrm{OC} 6 \mathrm{H} 4 \mathrm{SiO} 1.5$ ) 6 (IPhSiO 1.5 ) 2 ] with 1,4-Diethynylbenzene (DEB) Gives Through-Chain, Extended 3-D Conjugat. Macromolecules 2013, 46, 7580-7590. https://doi.org/10.1021/ma401422t.

(56) Furgal, J. C.; Jung, J. H.; Clark, S.; Goodson III, T.; Laine, R. M. Beads on a Chain (BoC) Phenylsilsesquioxane (SQ) Polymers via F- Catalyzed Rearrangements and ADMET or Reverse Heck Cross-Coupling Reactions: Through Chain, Extended Conjugation in 3-D with Potential for Dendronization. Macromolecules 2013, 46, 7591-7604. https://doi.org/10.1021/ma401423f.

(57) Guan, J.; Arias, J. J. R.; Tomobe, K.; Ansari, R.; Marques, M. de F. V; Rebane, A.; Mahbub, S.; Furgal, J. C.; Yodsin, N.; Jungsuttiwong, S.; et al. Unconventional Conjugation via VinylMeSi(O-)2 Siloxane Bridges May Imbue Semiconducting Properties in [Vinyl(Me)SiO(PhSiO1.5)8OSi(Me)Vinyl-Ar] Double-Decker Copolymers. ACS Appl. Polym. Mater. 2020. https://doi.org/10.1021/acsapm.0c00591.

(58) Walczak, M.; Januszewski, R.; Majchrzak, M.; Kubicki, M.; Dudziec, B.; Marciniec, B. Unusual: Cis and Trans Architecture of Dihydrofunctional Double-Decker Shaped Silsesquioxane and Synthesis of Its Ethyl Bridged $\pi$-Conjugated Arene Derivatives. New J. Chem. 2017, 41 (9), 3290-3296. https://doi.org/10.1039/c7nj00255f.

(59) Clarke, D.; Mathew, S.; Matisons, J.; Simon, G.; Skelton, B. W. Synthesis and Characterization of a Range of POSS Imides. Dye. Pigment. 2012, 92 (1), 659-667. https://doi.org/10.1016/j.dyepig.2011.05.028.

(60) Lenora, C. U.; Hu, N.; Furgal, J. C. Thermally Stable Fluorogenic Zn(II) Sensor Based on a Bis(Benzimidazole)Pyridine-Linked Phenyl-Silsesquioxane Polymer. ACS Omega 2020, 5 (51), 33017-33027. https://doi.org/10.1021/acsomega.0c04366.

(61) Laine, R. M.; Guan, J.; Sun, Z.; Ansari, R.; Endo, A.; Unno, M.; Liu, Y.; Ouali, A.; Mahbub, S.; Furgal, J. C.; et al. Conjugated Copolymers That Shouldn't Be. Angew. Chemie Int. Ed. 2021, anie.202014932. https://doi.org/10.1002/anie.202014932.

(62) Pyo, K.; Thanthirige, V. D.; Yoon, S. Y.; Ramakrishna, G.; Lee, D. Enhanced Luminescence of Au22(SG)18 Nanoclusters via Rational Surface Engineering. Nanoscale 2016, 8 (48), 20008-20016. https://doi.org/10.1039/c6nr07660b.

(63) Grubisic, Z.; Rempp, P.; Bnoit, H. A Universal Calibration for Gel Permeation. J. Polym. Sci. Part B Polym. Lett. 1967, 5 (9), 753-759.

(64) Gellerstedt, G. 8.1 Gel Permation Chromatography. Methods Lignin Chem. 1992, 487.

(65) Prokai, L.; Stevens, S. M.; Simonsick, W. J. Size-Exclusion Chromatography Coupled to Mass Spectrometry and Tandem Mass Spectrometry for Oligomer Analysis. 2004, No. 2, 196-207. https://doi.org/10.1021/bk-2005-0893.ch012.

(66) Moore, J. C. Gel Permeation Chromatography. I. A New Method for Molecular Weight Distribution of High Polymers. J. Polym. Sci. Part A Gen. Pap. 1964, 2 (2), 835-843. https://doi.org/10.1002/pol.1964.100020220.

(67) Radke, W. Size-Exclusion Chromatography Gradients. Encycl. Anal. Chem. 2015. 
https://doi.org/10.1002/9780470027318.a9475.

(68) Snell, N. E.; Rao, V. P.; Seckinger, K. M.; Liang, J.; Leser, J.; Mancini, A. E.; Rizzo, M. A. Homotransfer FRET Reporters for Live Cell Imaging. Biosensors 2018, 8 (4). https://doi.org/10.3390/bios8040089.

(69) Bader, A. N.; Hofman, E. G.; Voortman, J.; Van Bergen En Henegouwen, P. M. P.; Gerritsen, H. C. Homo-FRET Imaging Enables Quantification of Protein Cluster Sizes with Subcellular Resolution. Biophys. J. 2009, 97 (9), 2613-2622. https://doi.org/10.1016/j.bpj.2009.07.059.

(70) Bader, A. N.; Hoetzl, S.; Hofman, E. G.; Voortman, J.; Van Bergen En Henegouwen, P. M. P.; Van Meer, G.; Gerritsen, H. C. Homo-FRET Imaging as a Tool to Quantify Protein and Lipid Clustering. ChemPhysChem 2011, 12 (3), 475-483. https://doi.org/10.1002/cphc.201000801.

(71) Conroy, E. M.; Li, J. J.; Kim, H.; Algar, W. R. Self-Quenching, Dimerization, and HomoFRET in Hetero-FRET Assemblies with Quantum Dot Donors and Multiple Dye Acceptors. J. Phys. Chem. C 2016, 120 (31), 17817-17828. https://doi.org/10.1021/acs.jpcc.6b05886.

(72) Paila, Y. D.; Kombrabail, M.; Krishnamoorthy, G.; Chattopadhyay, A. Oligomerization of the Serotonin1A Receptor in Live Cells: A Time-Resolved Fluorescence Anisotropy Approach. J. Phys. Chem. B 2011, 115 (39), 11439-11447. https://doi.org/10.1021/jp201458h.

(73) Hwan Jung, J.; Furgal, J. C.; Goodson, T.; Mizumo, T.; Schwartz, M.; Chou, K.; Vonet, J. F.; Laine, R. M. 3-D Molecular Mixtures of Catalytically Functionalized [VinylSiO 1.5] 10/[VinylSiO 1.5] 12. Photophysical Characterization of Second Generation Derivatives. Chem. Mater. 2012, 24 (10), 1883-1895. https://doi.org/10.1021/cm300587s.

(74) Furgal, J. C.; Jung, J. H.; Goodson, T.; Laine, R. M. Analyzing Structure-Photophysical Property Relationships for Isolated T8, T10, and T12 Stilbenevinylsilsesquioxanes. J. Am. Chem. Soc. 2013, 135 (33), 12259-12269. https://doi.org/10.1021/ja4043092.

(75) Mahbub, S.; Furgal, J. C. Unpublished Results; 2018.

(76) Martín, R.; Prieto, P.; Carrillo, J. R.; Rodríguez, A. M.; De Cozar, A.; Boj, P. G.; DíazGarcía, M. A.; Ramírez, M. G. Design, Synthesis and Amplified Spontaneous Emission of 1,2,5-Benzothiadiazole Derivatives. J. Mater. Chem. C 2019, 7 (32), 9996-10007. https://doi.org/10.1039/c9tc03148k.

(77) Misra, R.; Gautam, P.; Jadhav, T.; Mobin, S. M. Donor - Acceptor Ferrocenyl-Substituted Benzothiadiazoles: Synthesis, Structure, and Properties. 2013.

(78) Togashi, D. M.; Nicodem, D. E. Photophysical Studies of 9,10-Phenanthrenequinones. Spectrochim. Acta - Part A Mol. Biomol. Spectrosc. 2004, 60 (13), 3205-3212. https://doi.org/10.1016/j.saa.2004.03.003.

(79) Kumar, V. R.; Rajkumar, N.; Ariese, F.; Umapathy, S. Direct Observation of Thermal Equilibrium of Excited Triplet States of 9,10-Phenanthrenequinone. A Time-Resolved Resonance Raman Study. J. Phys. Chem. A 2015, 119 (40), 10147-10157. 
https://doi.org/10.1021/acs.jpca.5b07972.

(80) Bohning, J. J.; Weiss, K. A Kinetic Study of the Photochemical Reaction of Phenanthrenequinone with Olefins. J. Am. Chem. Soc. 1966, 88 (13), 2893-2898. https://doi.org/10.1021/ja00965a002.

(81) Silva, R. S.; Nicodem, D. E. Solvent and Temperature Effects on the Phosphorescene of 9,10-Phenanthrenequinone in Fluid Solution. J. Photochem. Photobiol. A Chem. 2004, 162 (2-3), 231-238. https://doi.org/10.1016/j.nainr.2003.08.008.

(82) Mahbub, S.; Furgal, J. C. Synthesis and Steady State Photophysical Property Analysis of Beads on a Chain $(\mathrm{BoC})$ Silsesquioxane Oligomers Containing Phenylic and Heterocyclic Cross-Linkers. Silicon 2021, ASAP.

(83) Joseph, V.; Thomas, K. R. J.; Sahoo, S.; Singh, M.; Dubey, D. K.; Jou, J. H. Vinyl-Linked Cyanocarbazole-Based Emitters: Effect of Conjugation and Terminal Chromophores on the Photophysical and Electroluminescent Properties. ACS Omega 2018, 3 (12), 1647716488. https://doi.org/10.1021/acsomega.8b02198.

(84) Kato, S. I.; Yamada, Y.; Hiyoshi, H.; Umezu, K.; Nakamura, Y. Series of CarbazolePyrimidine Conjugates: Syntheses and Electronic, Photophysical, and Electrochemical Properties. J. Org. Chem. 2015, 80 (18), 9076-9090. https://doi.org/10.1021/acs.joc.5b01409.

(85) Quashie, A. Electronic and Molecular Structure of Carbazole Using Spectrophotometric and In Silico Methods. J. Nanosci. Nanotechnol. Appl. 2018, 2 (1), 1-12. https://doi.org/ISSN 2577-7920.

(86) Badaeva, E.; Harpham, M. R.; Guda, R.; Süzer, Ö.; Ma, C. Q.; Bäuerle, P.; Goodson, T.; Tretiak, S. Excited-State Structure of Oligothiophene Dendrimers: Computational and Experimental Study. J. Phys. Chem. B 2010, 114 (48), 15808-15817. https://doi.org/10.1021/jp109624d.

(87) Varnavski, O. P.; Ostrowski, J. C.; Sukhomlinova, L.; Twieg, R. J.; Bazan, G. C.; Goodson, T. Coherent Effects in Energy Transport in Model Dendritic Structures Investigated by Ultrafast Fluorescence Anisotropy Spectroscopy. J. Am. Chem. Soc. 2002, 124 (8), 1736-1743.

(88) Varnavski, O.; Leanov, A.; Liu, L.; Takacs, J.; Goodson, T. Large Nonlinear Refraction and Higher Order Nonlinear Optical Effects in a Novel Organic Dendrimer. J. Phys. Chem. B 2000, 104 (2), 179-188. https://doi.org/10.1021/jp9918353.

(89) Jonas, D. M.; Lang, M. J.; Nagasawa, Y.; Fleming, G. R. Energy Tranfer in the Photosynthetic Reaction Center. In Ultrafast Phenomena X; Barbara, P. F., Fujimoto, J. G., Knox, W. H., Zinth, W., Eds.; Springer Berlin Heidelberg: Berlin, Heidelberg, 1996; pp 336-337.

(90) Lakowicz, J. R. Introduction to Fluorescence. In Principles of Fluorescence Spectroscopy; New York, 2006; p 12. https://doi.org/10.1007/978-0-387-46312-4_19. 
